\title{
Management of dyslipidemia in Poland: Interdisciplinary Expert Position Statement endorsed by the Polish Cardiac Society Working Group on Cardiovascular Pharmacotherapy. The Fourth Declaration of Sopot
}

Filip M. Szymański ${ }^{1}$, Agnieszka Mickiewicz ${ }^{2}$, Grzegorz Dzida ${ }^{3}$, Iwona Gorczyca-Głowacka ${ }^{4}$, Dariusz Kozłowski ${ }^{5}$, Krystyna Widecka ${ }^{6}$, Zbigniew Krasiński ${ }^{7}$, Adam Kobayashi ${ }^{8,9}$, Dagmara Hering ${ }^{10}$, Katarzyna Mizia-Stec ${ }^{11}$, Jarosław D. Kasprzak ${ }^{12}$, Tomasz Zubilewicz ${ }^{13}$, Krzysztof Narkiewicz ${ }^{10}$, Marek Koziński ${ }^{14}$, Anna E. Płatek ${ }^{15}$, Anna Ryś-Czaporowska ${ }^{16}$, Beata Chełstowska ${ }^{17}$, Stefan Grajek ${ }^{18}$, Marcin Wełnicki ${ }^{19}$, Artur Mamcarz ${ }^{19}$, Marcin Barylski ${ }^{20}$, Beata Wożakowska-Kapłon ${ }^{4}$, Miłosz J. Jaguszewski ${ }^{2}$, Marcin Gruchała ${ }^{2}$, Krzysztof J. Filipiak ${ }^{21}$

${ }^{1}$ Department of Civilization Diseases, Faculty of Medicine, Collegium Medicum, Cardinal Stefan Wyszynski University in Warsaw, Poland; ${ }^{2} 1^{\text {st }}$ Department of Cardiology, Medical University of Gdansk,

Poland; ${ }^{3}$ Chair and Department of Internal Diseases, Medical University of Lublin, Poland; ${ }^{4} 1^{\text {st }}$ Department of Cardiology and Electrotherapy, Swietokrzyskie Cardiology Center, Faculty of Medical and Health Sciences, The University of Jan Kochanowski, Kielce, Poland; ${ }^{5}$ Department of Cardiology and

Electrotherapy, Medical University of Gdansk, Poland; ${ }^{6}$ Department of Hypertension and Internal Medicine, Pomeranian Medical University, Szczecin, Poland; ${ }^{7}$ Department of Vascular and Endovascular Surgery, Angiology and Phlebology, Institute of Surgery, Poznan University of Medical Sciences, Poznan,

Poland; ${ }^{8}$ Department of Pharmacology and Clinical Pharmacology, Faculty of Medicine, Collegium Medicum, Cardinal Stefan Wyszynski University in Warsaw, Poland; ${ }^{9}$ Department of Neurology with Stoke Unit, St. John Paul II Mazovian Provincial Hospital in Siedlce, Poland; ${ }^{10}$ Department of Hypertension and Diabetology, Medical University of Gdansk, Poland; ${ }^{11} 1^{\text {st }}$ Department of Cardiology, Medical University of Silesia, Katowice, Poland; ${ }^{12} 1^{\text {st }}$ Department of Cardiology, Medical University of Lodz, Poland;

${ }^{13}$ Department of Vascular Surgery and Angiology, Medical University of Lublin, Poland; ${ }^{14}$ Department of Cardiology and Internal Diseases, Institute of Maritime and Tropical Medicine, Gdynia, Poland;

${ }^{15}$ Department of Biophysics, Physiology and Pathophysiology, Medical University of Warsaw, Poland;

${ }^{16} 1^{\text {st }}$ Department of Cardiology, Medical University of Warsaw, Poland; ${ }^{17}$ Department of Biochemistry and Laboratory Diagnostics, Faculty of Medicine, Collegium Medicum, Cardinal Stefan Wyszynski University in Warsaw, Poland; ${ }^{18} 1^{\text {st }}$ Department of Cardiology, Poznan University of Medical Sciences, Poznan, Poland; ${ }^{19} 3^{\text {rd }}$ Department of Cardiology and Internal Diseases, Medical University of Warsaw, Poland; ${ }^{20}$ Department of Internal Medicine and Cardiac Rehabilitation, Medical University of Lodz, Poland;

${ }^{21}$ Institute of Clinical Sciences, Maria Sklodowska-Curie Medical Academy, Warsaw, Poland

This article has been co-published in the Choroby Serca i Naczyń 2021; 18(3): 95-120.

Address for correspondence: Prof. Filip M. Szymański, MD, PhD, Department of Civilization Diseases, Faculty of Medicine, Collegium Medicum, Cardinal Stefan Wyszynski University in Warsaw, ul. Wóycickiego 1/3, 01-938 Warszawa, Poland, e-mail: filip.szymanski@ptchc.pl

Received: 26.10.2021 Accepted: 26.10.2021 Early publication date: 17.11.2021

This article is available in open access under Creative Common Attribution-Non-Commercial-No Derivatives 4.0 International (CC BY-NC-ND 4.0) license, allowing to download articles and share them with others as long as they credit the authors and the publisher, but without permission to change them in any way or use them commercially. 


\section{Introduction}

Cardiovascular diseases still constitute the most frequent cause of both hospitalization and death worldwide. The classic modifiable risk factors for cardiovascular disease are malnutrition, smoking, low physical activity, increased blood pressure, prediabetes, overweight/obesity, elevated low-density lipoprotein cholesterol (LDL-C) in plasma, lowered high-density lipoprotein cholesterol (HDL-C) in plasma, and increased plasma triglycerides. However, the non-modifiable risk factors are age, sex, and early family history of ischemic heart disease or other artery diseases of atherosclerotic origin. The negative impact should also be remembered about the so-called non-classical risk factors for cardiovascular diseases, such as obstructive sleep apnea, air pollution, periodontal disease, or metabolic dysfunction - associated fatty liver disease (MAFLD). An independent risk factor for cardiovascular diseases is also an increased concentration of lipoprotein (a) - Lp(a).

The appropriate risk assessment based on both classical and non-classical risk factors is crucial when making therapeutic decisions that hence, influence the patient's prognosis.

In the first three documents [1-3], 10 conclusions were formulated to be a reference point in the debates of practicing physicians with experts during symposia/scientific conferences on the diagnosis/therapy of lipid disorder and the prevention of heart and vascular diseases. In the current document, the $11^{\text {th }}$ proposal relating to lipid-lowering treatment in the era of the coronavirus disease 2019 (COVID-19) pandemic has been added.

A common problem observed in everyday practice is the erroneous misuse of the term "hypercholesterolemia" to describe any form of a lipid disorders. Use of proper nomenclature in the medical records determine not only the type of recommended therapy but also the appropriate non-drug treatment. Dyslipidemia is defined as the occurrence of abnormal plasma levels of any lipid and/or lipoprotein fraction. The term of dyslipidemia encompasses all definitions given below [4]:

- hypercholesterolemia - plasma LDL-C level above the recommended values in a given cardiovascular risk category (see below); primary or secondary;

- familial hypercholesterolemia (FH) high plasma LDL-C level, usually correct plasma triglycerides level, monogenic ( $L D L R$, $A P O B, P C S K 9$ mutations) or polygenic; incidence 1 per $200-250$;
- familial combined hyperlipidemia - elevated triglycerides and LDL-C, a mutation in the upstream stimulatory factor 1 (USF1) gene; incidence 1 per 100-200;

- hypertriglyceridemia - plasma triglyceride level $>150 \mathrm{mg} / \mathrm{dL}(>1.7 \mathrm{mmol} / \mathrm{L})$ with normal LDL-C level;

- severe hypertriglyceridemia - plasma triglyceride level $\geq 500 \mathrm{mg} / \mathrm{dL}(\geq 5.6 \mathrm{mmol} / \mathrm{L})$;

- hyperlipoproteinemia (a) - genetically determined elevated plasma $\mathrm{Lp}$ (a) level $>50 \mathrm{mg} / \mathrm{dL}$; incidence 1 per 5 ;

Other rare genetic dyslipidemias:

- sitosterolemia - very high concentration of LDL-C, a mutation in the $A B C G 8$ and $A B C G 5$ genes disrupting the metabolism of phytosterols, inherited autosomal recessively; very rare incidence $<1$ per $1,000,000-5,000,000$;

- familial hypoalphalipoproteinemia - low concentration of HDL-C and correct LDL-C, a mutation in the apolipoprotein A-I (APOA1) gene, usually inherited autosomal dominant; incidence $<1$ per million;

- analfalipoproteinemia (Tangier disease) - very low concentration of HDL-C or lack of this cholesterol fraction, slightly elevated triglycerides, a mutation in the $A B C A 1$ ( $A T P$ -binding cassette transporter $A 1$, a protein that carries cholesterol esters) gene, inherited autosomal recessively; incidence of $<1$ per million;

- familial dysbetalipoproteinemia - elevated concentration of triglycerides and total cholesterol (TC), lowered concentration of HDL-C, a mutation in the apolipoprotein $E$ $(A P O E)$ gene, inherited autosomal dominant, incidence $1-5$ per 10,000 ;

- familial chylomicronemia - triglyceride concentration often $>1000 \mathrm{mg} / \mathrm{dL}(11.3$ $\mathrm{mmol} / \mathrm{L})$, low LDL-C concentration, the "flotation test" positive, conditioned e.g., lipoprotein lipase (LPL) deficiency or rarely mutations associated with LPL function, i.e., $A P O C 2$, APOA5, LMF1, GPIHBP1, inherited autosomal recessively; incidence 1-9 per million;

- congenital lipodystrophy (Berardinelli-Seipa syndrome) - elevated triglycerides, mutation of AGPAT2 and BSCL-2 (seipin) genes, inherited autosomal recessively; incidence 1-9 per million;

- familial deficiency of lecithin-cholesterol acyltransferase - low concentration of HDL-C, a mutation in lecithin cholesterol acyltransferase $(L C A T)$ gene; incidence $<1$ per million; 
- familial hypercholesterolemia inherited autosomal recessively - high concentration of LDL-C, caused by a homozygous mutation in the LDL receptor adapter protein (LDLRAP1) — incidence $<1$ per million.

In the diagnostic process, attention should be paid to possible secondary reasons of dyslipidemia, which may be responsible for up to $30-40 \%$ of dyslipidemia cases:

- lifestyle - alcohol abuse, insufficient physical activity, a high-fat diet rich in saturated fats, high carbohydrate intake;

- diseases - hypothyroidism (including subclinical), improperly controlled diabetes, overweight, obesity, chronic kidney disease, nephrotic syndrome, hepatic cholestasis, primary biliary cirrhosis, Cushing's syndrome, dysgammaglobulinemia, connective tissue diseases, i.e., rheumatoid arthritis and systemic lupus erythematosus;

- pregnancy - high values of lipid profile components relate to the physiological image of pregnancy, especially at a later stage, with normalization in the puerperium. Quantitative and qualitative changes in the lipid profile are observed. An increase in the concentration of triglycerides dominates (even by several times, but concentrations above $300 \mathrm{mg} / \mathrm{dL}$ are rarely achieved), the concentration of LDL-C may increase by up to $40 \%$, and the concentration of HDL-C by $15-25 \%$. These changes are adaptive, and the concentrations of individual cholesterol fractions return to pre-pregnancy values within about half a year of its termination;

- drugs - corticosteroids, anabolic steroids, oral progestogens and estrogens (oral contraceptives, hormone replacement therapy), selective estrogen receptor modulators (e.g., tamoxifen), retinoids, beta-blockers, thiazide diuretics (chlorthalidone), ciclosporin, mTOR kinase inhibitors (rapamycin, everolimus), cyclophosphamide, protease inhibitors used in the treatment of human immunodeficiency virus (HIV) (e.g., lopinavir, ritonavir), interferon, L-asparaginase, cyclophosphamide, atypical antipsychotics.

\section{Familial hypercholesterolemia}

In everyday clinical practice, $\mathrm{FH}$ remains a major challenge. Based on the molecular origin, polygenic and monogenic FH may be distinguished.

The monogenic $\mathrm{FH}$ is caused by the mutations in genes encoding proteins that participate in the metabolism of LDL-C particles - LDL receptor (85-95\% of cases), rarely B-100 apolipoprotein (APOB-100) or proprotein convertase subtilisin/ /kexin type 9 (PCSK9). The disease is inherited autosomal dominantly. Incidence of heterozygous form 1 per 200-250 births, while homozygous 1 per $160,000-300,000$ [4, 5].

The most important abnormality in heterozygous $\mathrm{FH}(\mathrm{HeFH})$ is the increased concentration of LDL-C in the blood observed from birth, usually in the range of $200-400 \mathrm{mg} / \mathrm{dL}$. The deposition of cholesterol in tissues may lead to the formation of corneal arcus at a young age ( $<45$ years of age), and tendinous xanthomata (Achilles, subpatellar, and extensors of fingers of the hand). Recurrent pain in tendons, their nodules, or inflammation should therefore be a prerequisite for lipid profile control.

The risk of coronary artery disease (CAD) development in patients with definite or probable HeFH is increased by at least 10 times. It is estimated that if patients with $\mathrm{HeFH}$ are left untreated, premature atherosclerotic cardiovascular disease (ASCVD) occurs in about $25 \%$ of women and about $50 \%$ of men. When implemented early, long-term, and effective lipid-lowering therapy can significantly reduce this risk $[4,6,7]$.

Familial hypercholesterolemia diagnosis should be considered in adults with premature CAD (women $<60$ years of age and men $<55$ years of age) and elevated LDL-C levels $>190 \mathrm{mg} / \mathrm{dL}$ [1]. The clinical diagnosis of $\mathrm{FH}$ is established on the modified Dutch Lipid Clinic Network (DLCN) criteria based on clinical data including medical history, physical examination, and lipid profile results, rarely on the basis of genetic tests confirming the presence of mutations in the previously described genes (Table 1) [8, 9].

According to the current recommendations, genetic tests may facilitate and accelerate the diagnosis but are not required for that purpose. Due to the high costs and low availability of genetic tests, it is recommended that further tests for $\mathrm{HeFH}$ be subjected to people with a probable or definite clinical diagnosis on the DLCN scale [1]. However, genetic tests cannot be a criterion for possible therapeutic programs or reimbursement, as they will limit the availability of novel treatment.

The most effective way to identify new cases of $\mathrm{FH}$ is cascade diagnostics in relatives of the identified proband based on TC or LDL-C or the presence of $L D L R, A P O B$, or PCSK9 mutations (if the test was performed) [10].

Approximately $20-40 \%$ of patients with a clinical diagnosis of $\mathrm{FH}$ fail to confirm mutations in the 
Table 1. Diagnostic criteria for familial hypercholesterolemia (by: the Dutch Lipid Clinic Network scale) $[8,9]$.

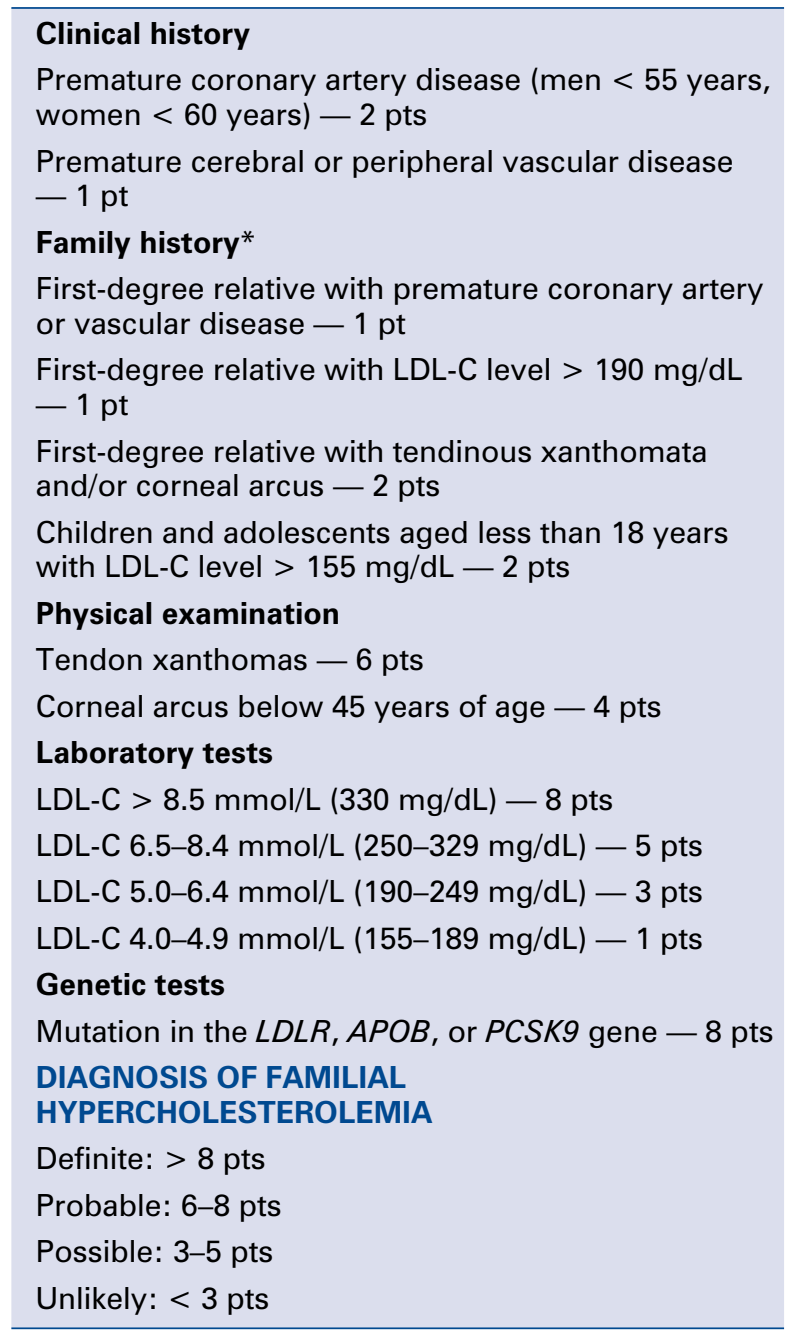

*Scoring for 1 or 2 and point 3 or 4; LDL-C - low-density lipoprotein cholesterol

LDLR, APOB, and PCSK9 genes. This suggests the polygenic origin of hypercholesterolemia. It has been proven that the accumulation of single nucleotide polymorphisms (SNPs), which individually slightly increase the concentration of LDL-C, may increase its concentration to values similar to those in patients with monogenic $\mathrm{FH}$. The clinical picture of polygenic hypercholesterolemia is similar to that of monogenic $\mathrm{FH}$, however, in the case of polygenic hypercholesterolemia, only $30 \%$ of relatives of the patient have an elevated LDL-C level. Moreover, the results of the studies indicate that the cardiovascular risk is lower in polygenic than in monogenic $\mathrm{FH}$, which is probably caused by burden of LDL-C over the years. In monogenic $\mathrm{FH}$, high concentration of LDL-C occurs from birth, while in polygenic $\mathrm{FH}$, environmental factors have an additive effect on the concentration of LDL-C [11-13].

\section{Theses of the Declaration}

1. Dyslipidemia is the most common risk factor for cardiovascular disease in Poland. Epidemiological analyses from the WOBASZ and WOBASZ II studies indicate that in 2013-2014 (WOBASZ II study), hypercholesterolemia was present in $70.3 \%$ of men and $64.3 \%$ of women in a representative sample of adult Poles [14]. Described data are even more important due to the fact that European studies in patients with established coronary heart disease, such as the EUROASPIRE-IV study, show that the LDL-C level is elevated in more than $80 \%$ of these patients, and despite the wide use of statins, only $19.3 \%$ of patients achieve target lipid levels $[15,16]$.

Simultaneously, studies on the effect of cardiovascular risk factor modification over the last two decades indicate that the increase in the mean length of life in Poland has been mostly related to a reduction in mortality caused by coronary heart disease [17]. Using the IMPACT model, it was shown that a reduction in the mean cholesterol level in the Polish population that was seen in the last decades accounted for $39 \%$ of the reduction in CAD mortality [17]. These findings highlight the need for wide-ranging efforts to reduce cholesterol concentrations at the individual and population level.

2. The low detection rate of lipid disorders is one of the reasons for ineffective treatment. During the COVID-19 pandemic, a significant decrease in biochemical tests performance, including lipid profiles, was observed. It should be recalled that currently, routine lipid profile testing is recommended in all men above 40 years of age and in all women who are postmenopausal or above 50 years of age [18]. Such late testing for plasma cholesterol level, without including it in periodic health checks or occupational medicine testing panels, may reduce the opportunity for early detection of severe hypercholesterolemia. The following clinical conditions may predispose people for earlier testing, and therefore at least every adult, testing:

- established cardiovascular disease;

- established peripheral arterial disease;

- diabetes;

- obesity;

- hypertension;

- moderate or severe chronic kidney disease;

- high, very high, or extremely high cardiovascular risk; 
- autoimmune inflammatory diseases (i.e., rheumatoid arthritis, systemic lupus erythematosus, or psoriasis);

- gestational diabetes;

- hypertension in pregnancy;

- clinical manifestations of dyslipidemia (such as tendon xanthomas, xanthelasma, or corneal lipid degeneration [corneal arcus]);

- family history of lipid disorders or premature cardiovascular disease;

- antiretroviral treatment.

In all cases, testing should include direct TC and triglyceride level measurements and calculation of LDL-C (using the Friedewald formula) and non-HDL cholesterol (non-HDL-C) levels. In case of hypertriglyceridemia ( $>400 \mathrm{mg} / \mathrm{dL}$ [ $>4.5$ $\mathrm{mmol} / \mathrm{L}]$ ), direct LDL-C level measurement is necessary. It is not justified to measure single lipid fractions without evaluation of the full lipid profile, and additional measurements of apolipoprotein $B$ (apoB), apolipoprotein A (apoA), Lp(a) levels and determinations of the apoB to apoA ratio and the non-HDL-C to HDL-C ratio may be considered in selected clinical settings. Traditionally, lipid levels are measured in fasting conditions but studies indicate that measurements of most lipid parameters yield similar values in postprandial and fasting conditions. The exception is triglyceride level which shows a postprandial increase by about $30 \mathrm{mg} / \mathrm{dL}$ $(0.3 \mathrm{mmol} / \mathrm{L})$ [19].

Determination of $\mathrm{Lp}(\mathrm{a})$ concentration is recommended in selected subjects at high cardiovascular risk or in order to clarify the classification in the European guidelines (point 7 of the Declaration). According to the current recommendation of European experts, the determination of $\mathrm{Lp}(\mathrm{a})$ concentration may be considered at least once in a lifetime in every adult [4].

Following initiation of lipid-lowering therapy, lipid profile should be evaluated every $8 \pm 4$ weeks to adjust therapy until target lipid levels are achieved. In patients with adequate on-treatment lipid levels, annual lipid profile testing is recommended. In addition, creatine kinase $(\mathrm{CK})$ and alanine aminotransferase (ALT) levels should be evaluated prior to the initiation of lipid-lowering therapy. Single ALT level retesting is indicated at $8-12$ weeks after lipid-lowering therapy initiation or dose escalation. Further routine CK and ALT level retesting are not necessary unless prompted by clinical symptoms [20].

\section{The individual goal of lipid-lowering} therapy depends on the cardiovascular risk. In order to plan lipid-lowering treatment, it is impor- tant to comprehensively assess the patient's health condition, taking into account the presence of classical and non-classical cardiovascular risk factors. According to the previous recommendations on the prevention of cardiovascular diseases, a risk assessment should be based on the SCORE scale in modification proposed for the Polish population [21]. Recently, a new SCORE2 risk assessment scale based on non-HDL-C has been proposed in the "European Heart Journal". Contrary to SCORE, it is not calibrated for data from Poland, however, it is possible to use the calculation of the category of high-risk countries for Polish patients. The SCORE2 and SCORE2-OP scales have been introduced as currently applicable to the new guidelines of the European Society of Cardiology 2021 on the prevention of heart and vascular diseases 2021. The document includes 4 forms that differ in the baseline cardiovascular risk (Fig. 1A-D) [22]. Also proposed herein, cardiovascular risk categories modified on the basis of the new guidelines, which are presented in Table 2 [22].

Besides the low, moderate, high, and very high cardiovascular risk categories, the extremely high risk group has remained to be defined as a condition after multiple cardiovascular events and/or revascularizations, percutaneous left main stem stenting or/and multivessel CAD (comprehensive angioplasty in multivessel coronary disease), generalized atherosclerosis - multiple vascular beds with additional risk factors or the progression of atherosclerotic cardiovascular disease in patients who achieved and consistently maintained LDL-C $<55 \mathrm{mg} / \mathrm{dL}(<1.4 \mathrm{mmol} / \mathrm{L})$.

After cardiovascular risk assessment, intervention should be planned appropriately. The primary therapeutic goal is to achieve the target LDL-C concentration based on the patient's cardiovascular risk. The results of the latest studies indicate that a very significant reduction of LDL-C is associated with an improved prognosis of patients, a reduction in the risk of cardiovascular events, and a reduction in the severity of atherosclerotic changes in blood vessels [22, 23]. After achieving the target LDL-C concentration, a secondary goal is to achieve the target non-HDL-C concentration. The results of previous studies have revealed that both in the group of women and in the group of men there is a significant increase in the risk of cardiovascular events along with the increase in the concentration of non-HDL-C (Fig. 2) [25].

After achieving the target levels of LDL-C and non-HDL-C a practicing physician may set additional goals (e.g., triglyceride levels) (Table 3). 


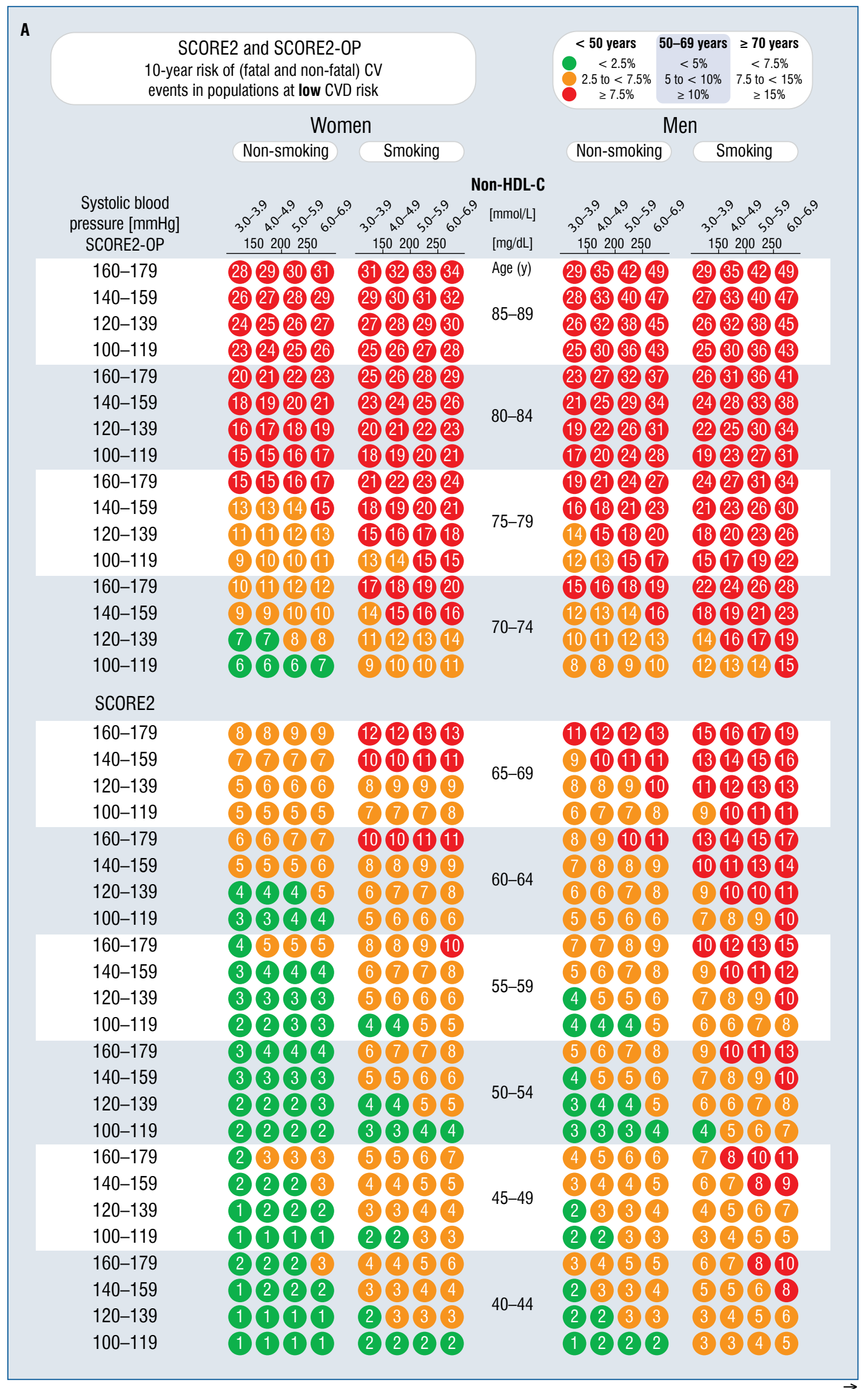




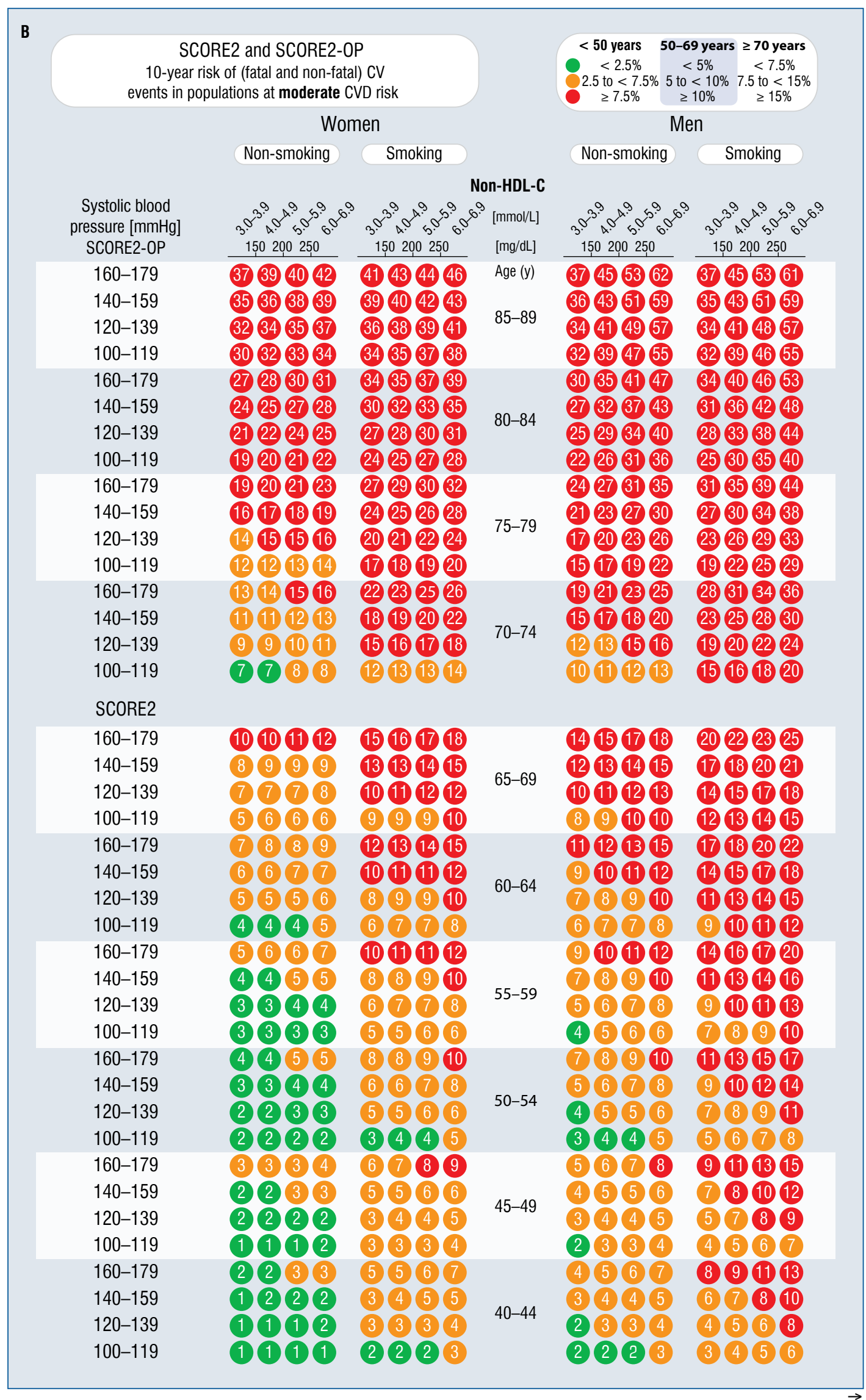




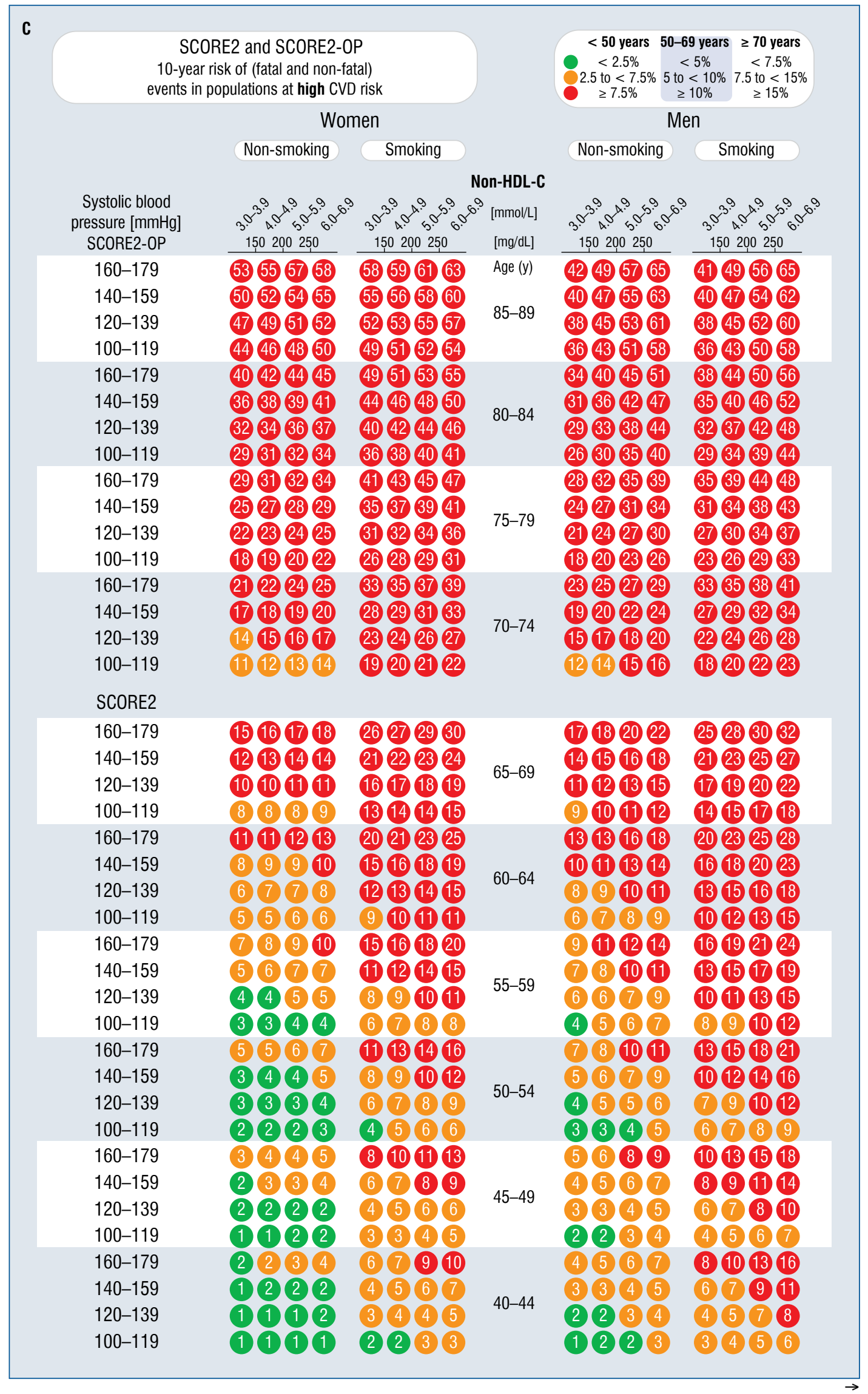




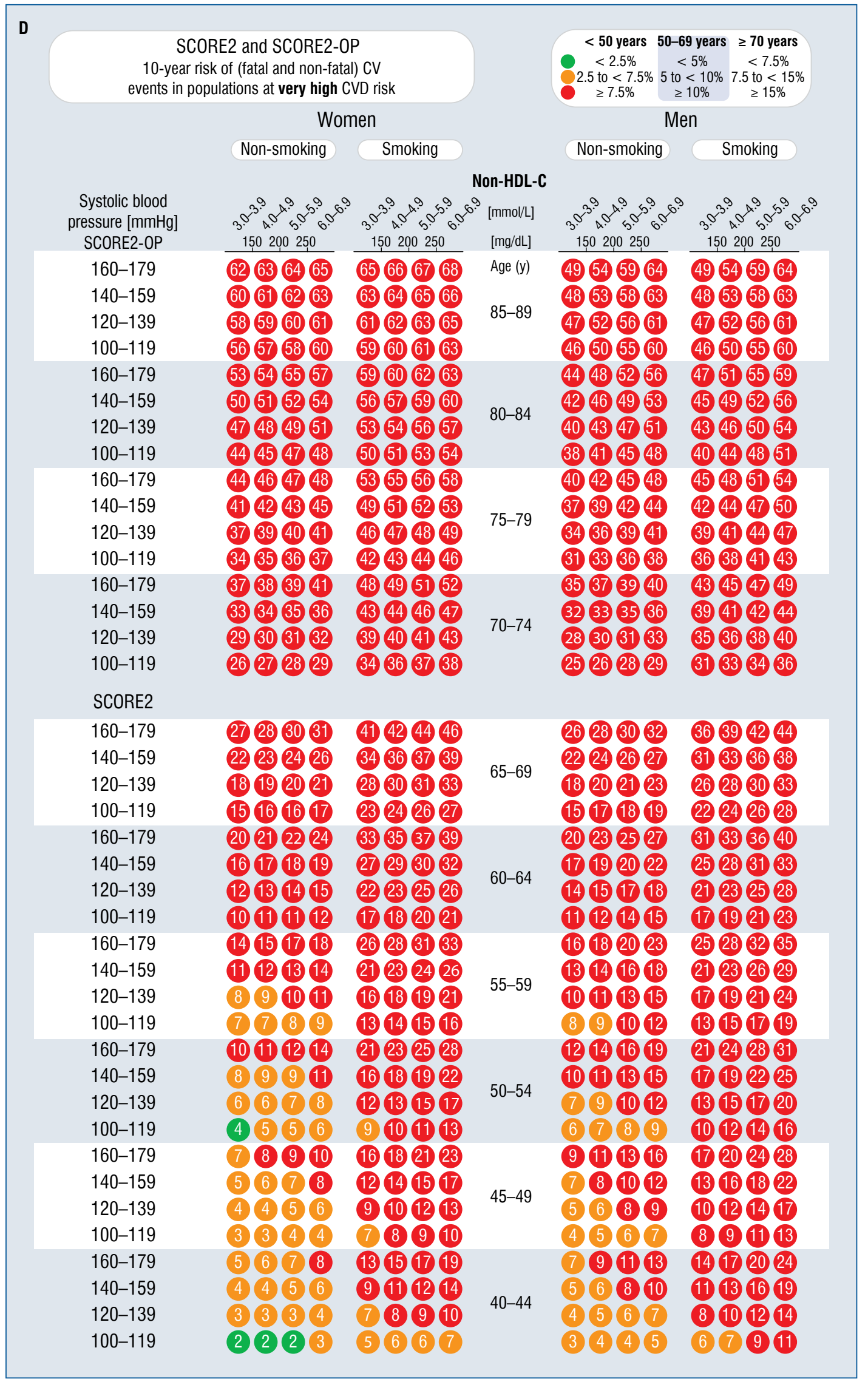

Figure 1. SCORE2 and SCORE2-OP risk assessment scale; A. Low risk; B. Moderate risk; C. High risk; D. Very high risk (source: [22]); SCORE — Systematic Coronary Risk Estimation; CV — cardiovascular; CVD — cardiovascular disease; non-HDL-C — non-high-density lipoprotein cholesterol. 
Table 2. Cardiovascular risk categories according to the latest guidelines of the European Society of Cardiology 2021 on the prevention of cardiovascular diseases (CVD) (source: [22]).

\begin{tabular}{|c|c|c|c|}
\hline Patient category & Subgroups & $\begin{array}{l}\text { Risk } \\
\text { categories }\end{array}$ & $\begin{array}{l}\text { CVD risk and therapy benefit } \\
\text { estimation }\end{array}$ \\
\hline \multicolumn{4}{|c|}{ Apparently healthy persons } \\
\hline \multirow[t]{3}{*}{$\begin{array}{l}\text { Persons without } \\
\text { established } \\
\text { ASCVD, DM, CKD, } \\
\text { familial hypercho- } \\
\text { lesterolemia }\end{array}$} & $<50$ years & $\begin{array}{l}\text { Low- to } \\
\text { high-risk }\end{array}$ & $\begin{array}{l}\text { 10-year CVD risk estimation (SCORE2). } \\
\text { Lifetime risk and benefit estimation } \\
\text { (e.g., with the LIFE-CVD lifetime model) } \\
\text { to facilitate the communication of CVD } \\
\text { risk and treatment benefits }\end{array}$ \\
\hline & $50-69$ years & $\begin{array}{l}\text { Low- to very } \\
\text { high-risk }\end{array}$ & $\begin{array}{l}\text { 10-year CVD risk estimation (SCORE2). } \\
\text { Lifetime benefit estimation of risk factor } \\
\text { treatment (e.g., with the LIFE-CVD life- } \\
\text { time model) to facilitate the communica- } \\
\text { tion of treatment benefits }\end{array}$ \\
\hline & $\geq 70$ years & $\begin{array}{l}\text { Low- to very } \\
\text { high-risk }\end{array}$ & $\begin{array}{l}\text { 10-year CVD risk estimation (SCORE2-OP). } \\
\text { Lifetime benefit estimation of risk factor } \\
\text { treatment (e.g., with the LIFE-CVD } \\
\text { lifetime model) to facilitate the } \\
\text { communication of treatment benefits }\end{array}$ \\
\hline \multicolumn{4}{|l|}{ Patients with CKD } \\
\hline \multirow[t]{4}{*}{$\begin{array}{l}\text { CKD without } \\
\text { diabetes } \\
\text { or ASCVD }\end{array}$} & $\begin{array}{l}\text { Moderate CKD } \\
\left(\mathrm{eGFR} 30-44 \mathrm{~mL} / \mathrm{min} / 1.73 \mathrm{~m}^{2}\right. \\
\text { and ACR }<30 \text { or }\end{array}$ & High-risk & $\mathrm{N} / \mathrm{A}$ \\
\hline & $\begin{array}{l}\text { eGFR } 45-59 \mathrm{~mL} / \mathrm{min} / 1.73 \mathrm{~m}^{2} \\
\text { and ACR } 30-300 \text { or }\end{array}$ & & \\
\hline & $\begin{array}{l}\text { eGFR } \geq 60 \mathrm{~mL} / \mathrm{min} / 1.73 \mathrm{~m}^{2} \\
\text { and } A C R>300 \text { ) }\end{array}$ & & \\
\hline & $\begin{array}{l}\text { Severe CKD (eGFR }<30 \mathrm{~mL} / \\
/ \mathrm{min} / 1.73 \mathrm{~m}^{2} \text { or eGFR } 30-44 \mathrm{~mL} / \\
/ \mathrm{min} / 1.73 \mathrm{~m}^{2} \\
\text { and ACR }>30)\end{array}$ & Very high-risk & $\mathrm{N} / \mathrm{A}$ \\
\hline \multicolumn{4}{|c|}{ Familial hypercholesterolemia } \\
\hline $\begin{array}{l}\text { Associated with } \\
\text { markedly elevated } \\
\text { cholesterol levels }\end{array}$ & N/A & High-risk & $\mathrm{N} / \mathrm{A}$ \\
\hline \multicolumn{4}{|c|}{ Patients with type 2 diabetes mellitus } \\
\hline \multirow[t]{3}{*}{$\begin{array}{l}\text { Patients with type } \\
1 \text { DM above ac- } \\
\text { cording to these } \\
\text { criteria }\end{array}$} & $\begin{array}{l}\text { Patients with well controlled } \\
\text { short-standing DM (e.g., }<10 \\
\text { years), no evidence of TOD and } \\
\text { no additional ASCVD risk factors }\end{array}$ & Moderate- risk & $\mathrm{N} / \mathrm{A}$ \\
\hline & $\begin{array}{l}\text { Patients with DM without } \\
\text { ASCVD and/or severe TOD, and } \\
\text { not fulfilling the moderate } \\
\text { risk criteria }\end{array}$ & High-risk & $\begin{array}{l}\text { Residual } 10 \text {-year CVD risk estimation } \\
\text { after general prevention goals (e.g., } \\
\text { with the ADVANCE risk score or DIAL } \\
\text { model). Consider lifetime CVD risk and } \\
\text { benefit estimation of risk factor treat- } \\
\text { ment (e.g., DIAL model) }\end{array}$ \\
\hline & $\begin{array}{l}\text { Patients with DM with } \\
\text { established ASCVD } \\
\text { and/or severe TOD: } \\
\text { - eGFR }<45 \mathrm{~mL} / \mathrm{min} / 1.73 \mathrm{~m}^{2} \\
\text { irrespective of albuminuria } \\
\text { - eGFR } 45-59 \mathrm{~mL} / \mathrm{min} / 1.73 \mathrm{~m}^{2} \\
\text { and microalbuminuria } \\
\text { (ACR } 30-300 \mathrm{mg} / \mathrm{g} \text { ) } \\
\text { - proteinuria (ACR > } 300 \mathrm{mg} / \mathrm{g} \text { ) } \\
\text { - presence of microvascular dis- } \\
\text { ease in at least } 3 \text { different sites } \\
\text { (e.g., microalbuminuria plus } \\
\text { retinopathy plus neuropathy) }\end{array}$ & Very high-risk & $\begin{array}{l}\text { Residual } 10 \text {-year CVD risk estimation } \\
\text { after general prevention goals (e.g., } \\
\text { with the SMART risk score for estab- } \\
\text { lished CVD or with the ADVANCE risk } \\
\text { score or with the DIAL model). Con- } \\
\text { sider lifetime CVD risk and benefit } \\
\text { estimation of risk factor treatment } \\
\text { (e.g., DIAL model) }\end{array}$ \\
\hline
\end{tabular}


Table 2 (cont.). Cardiovascular risk categories according to the latest guidelines of the European Society of Cardiology 2021 on the prevention of cardiovascular diseases (CVD) (source: [22]).

\begin{tabular}{|c|c|c|c|}
\hline Patient category & Subgroups & $\begin{array}{l}\text { Risk } \\
\text { categories }\end{array}$ & $\begin{array}{l}\text { CVD risk and therapy benefit } \\
\text { estimation }\end{array}$ \\
\hline \multicolumn{4}{|c|}{ Patients with established ASCVD } \\
\hline $\begin{array}{l}\text { Documented } \\
\text { ASCVD, clinical or } \\
\text { unequivocal } \\
\text { on imaging. Docu- } \\
\text { mented clinical } \\
\text { ASCVD includes } \\
\text { previous AMI, } \\
\text { ACS, coronary } \\
\text { revascularization } \\
\text { and other arterial } \\
\text { revascularization } \\
\text { procedures, stroke } \\
\text { and TIA, aortic } \\
\text { aneurysm and } \\
\text { PAD. Unequivo- } \\
\text { cally documented } \\
\text { ASCVD on imaging } \\
\text { includes plaque on } \\
\text { coronary angio- } \\
\text { graphy or carotid } \\
\text { ultrasound or on } \\
\text { CTA. It does NOT } \\
\text { include some } \\
\text { increase in con- } \\
\text { tinuous imaging } \\
\text { parameters such } \\
\text { as intima-media } \\
\text { thickness of the } \\
\text { carotid artery }\end{array}$ & N/A & Very high-risk & $\begin{array}{l}\text { Residual CVD risk estimation after gen- } \\
\text { eral prevention goals (e.g., } 10 \text {-year risk } \\
\text { with the SMART risk score for patients } \\
\text { with established CVD or } 1 \text { - or } 2 \text {-year } \\
\text { risk with EUROASPIRE risk score for } \\
\text { patients with CHD). Consider lifetime } \\
\text { CVD risk and benefit estimation of risk } \\
\text { factor treatment (e.g., SMART-REACH } \\
\text { model; or DIAL model if diabetes) }\end{array}$ \\
\hline
\end{tabular}

ACR - albumin-to-creatinine ratio (to convert $\mathrm{mg} / \mathrm{g}$ to $\mathrm{mg} / \mathrm{mmol}$ : divide by 10 ); ACS - acute coronary syndrome; ADVANCE - Action in Diabetes and Vascular disease: preterAx and diamicroN-MR Controlled Evaluation; AMI — acute myocardial infarction; ASCVD - atherosclerotic cardiovascular disease; CHD - coronary heart disease; CKD — chronic kidney disease; CTA - computed tomography angiography; DIAL — Diabetes lifetime-perspective prediction; DM — diabetes mellitus; eGFR - estimated glomerular filtration rate; IMT — intima-media thickness; LIFE-CVD — LIFEtime-perspective CardioVascular Disease; N/A — not applicable; PAD — peripheral artery disease; REACH Reduction of Atherothrombosis for Continued Health; SCORE - Systematic Coronary Risk Estimation; SMART — Secondary Manifestations of Arterial Disease; TIA — transient ischemic attack; TOD — target organ damage

This document maintains the category of "extremely high cardiovascular risk", which is based on the Third Sopot Declaration and guidelines of the American endocrine societies (Tables 2 and 3) [23].

4. It is necessary to introduce standardised laboratory report forms. The expert consensus panel suggests a recommendation to standardize laboratory report forms so as they indicate target ranges in accordance with the most recent recommendations and medical knowledge and do not generate a risk of potential errors by patients or physicians. A proposal of such a form is shown in Figure 3.

It is not necessary to measure the fasting lipid profile. The only exception is triglycerides, which still absolutely must be measured in fasting conditions. Even in people with normal triglyceride levels (up to $150-179 \mathrm{mg} / \mathrm{dL}$ fasting), however, there may exist a status of lipid intolerance, common in patients with diabetes, are obese, or who are overweight. For these patients, the currently standardized fat tolerance test for postprandial lipemia is recommended. It is performed in people with normal fasting triglycerides, after refraining from a meal for 10-12 hours and measuring triglycerides again 4 hours after administration of a standardized fatty meal (Lipid Test $\mathrm{Control}^{\circledR}$ ). Triglyceride values $>220 \mathrm{mg} / \mathrm{dL}$ allow diagnoses of abnormal postprandial lipemia. Other lipidlowering drugs, apart from those listed in this chapter, including over-the-counter drugs, are not relevant in the lipid-lowering pharmacotherapy of patients at very high and extremely high cardiovascular risk. 


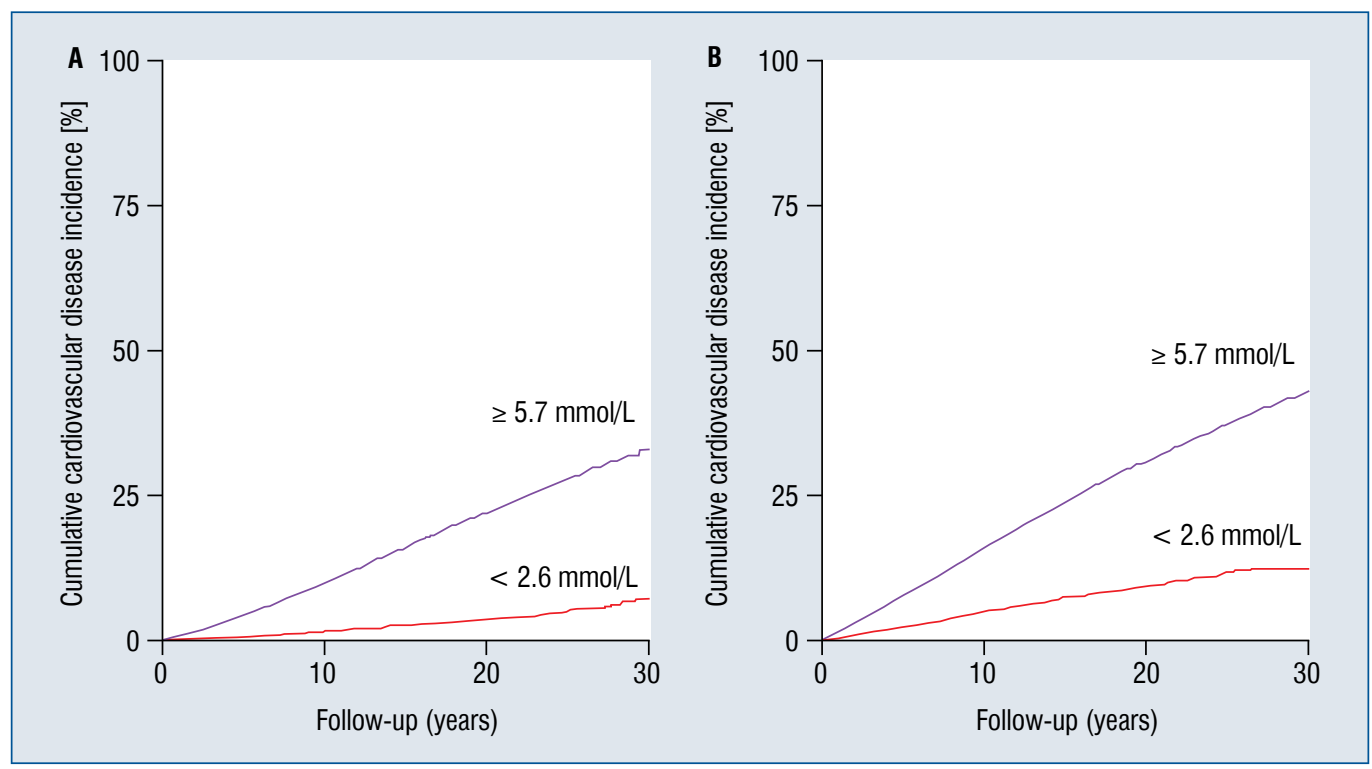

Figure 2. The risk of cardiovascular events depending on the non-high-density lipoprotein cholesterol (non-HDL-C) levels; A. Women; B. Men; $\mathrm{p}<0.0001$ (adapted from: [25], modified).

Table 3. Target concentration of low-density lipoprotein cholesterol (LDL-C), non-high-density lipoprotein cholesterol (non-HDL-C) and triglycerides (TG) depending on the cardiovascular risk profile (own work).

\begin{tabular}{lccc}
\hline Risk category & Primary goal - LDL-C & Secondary goal - non-HDL-C & Additional goal - TG \\
\hline EXTREMELY HIGH & $<35 \mathrm{mg} / \mathrm{dL}(<0.9 \mathrm{mmol} / \mathrm{L})$ & $<65 \mathrm{mg} / \mathrm{dL}(<1.7 \mathrm{mmol} / \mathrm{L})$ & $<150 \mathrm{mg} / \mathrm{dL}(<1.7 \mathrm{mmol} / \mathrm{L})$ \\
VERY HIGH & $<55 \mathrm{mg} / \mathrm{dL}(<1.4 \mathrm{mmol} / \mathrm{L})$ & $<85 \mathrm{mg} / \mathrm{dL}(<2.2 \mathrm{mmol} / \mathrm{L})$ & $<150 \mathrm{mg} / \mathrm{dL}(<1.7 \mathrm{mmol} / \mathrm{L})$ \\
HIGH & $<70 \mathrm{mg} / \mathrm{dL}(<1.8 \mathrm{mmol} / \mathrm{L})$ & $<100 \mathrm{mg} / \mathrm{dL}(<2.6 \mathrm{mmol} / \mathrm{L})$ & $<150 \mathrm{mg} / \mathrm{dL}(<1.7 \mathrm{mmol} / \mathrm{L})$ \\
MODERATE & $<100 \mathrm{mg} / \mathrm{dL}(<2.6 \mathrm{mmol} / \mathrm{L})$ & $<130 \mathrm{mg} / \mathrm{dL}(<3.4 \mathrm{mmol} / \mathrm{L})$ & $<150 \mathrm{mg} / \mathrm{dL}(<1.7 \mathrm{mmol} / \mathrm{L})$ \\
LOW & $<115 \mathrm{mg} / \mathrm{dL}(<3.0 \mathrm{mmol} / \mathrm{L})$ & $<145 \mathrm{mg} / \mathrm{dL}(<3.8 \mathrm{mmol} / \mathrm{L})$ & $<150 \mathrm{mg} / \mathrm{dL}(<1.7 \mathrm{mmol} / \mathrm{L})$
\end{tabular}

5. It is necessary to recommend lifestyle modifications in all patients. Non-drug treatment is the basis of therapy and translates into a reduction of cardiovascular risk, improvement of the patients' prognosis and functioning. When considering groups of patients with any atherosclerotic diseases, non-drug treatment consists of lifestyle modification in a broad sense. A change in nutrition is the basic approach that allows reducing LDL-C levels. However, a healthy diet does not only reduce lipid levels but also has a beneficial effect on other cardiovascular risk factors beyond the LDL-C level. Nutrition has a role mostly in the prevention and treatment of mild and moderate hypercholesterolemia in primary prevention, and of atherogenic dyslipidemia, particularly by its effect on triglycerides, small dense LDL-C, and low HDL-C levels which are associated with obesity and insulin resistance. An example of the food products' impact on the reduction of LDL-C is presented in Table 4 [26].

The major components of the dietary approach in subjects with lipid disorders include reduction of total fat intake to $25-35 \%$ of the overall energy intake, saturated fat intake to $7 \%$ of the overall energy intake, and cholesterol intake to $<200 \mathrm{mg}$ daily [16-21, 23, 24, 27, 28]. In particular, saturated fatty acids are a nutritional factor that has the strongest effect on LDL-C level. It has been estimated that per each additional $1 \%$ of energy intake from saturated fat, serum LDL-C level increases by $0.8-1.6 \mathrm{mg} / \mathrm{dL}[17-21,23,24,27,28]$. Dietary treatment of hypertriglyceridemia should include reduction of alcohol, carbohydrate intake, in particular intake of simple sugars, and weight loss should be recommended in obese subjects. 


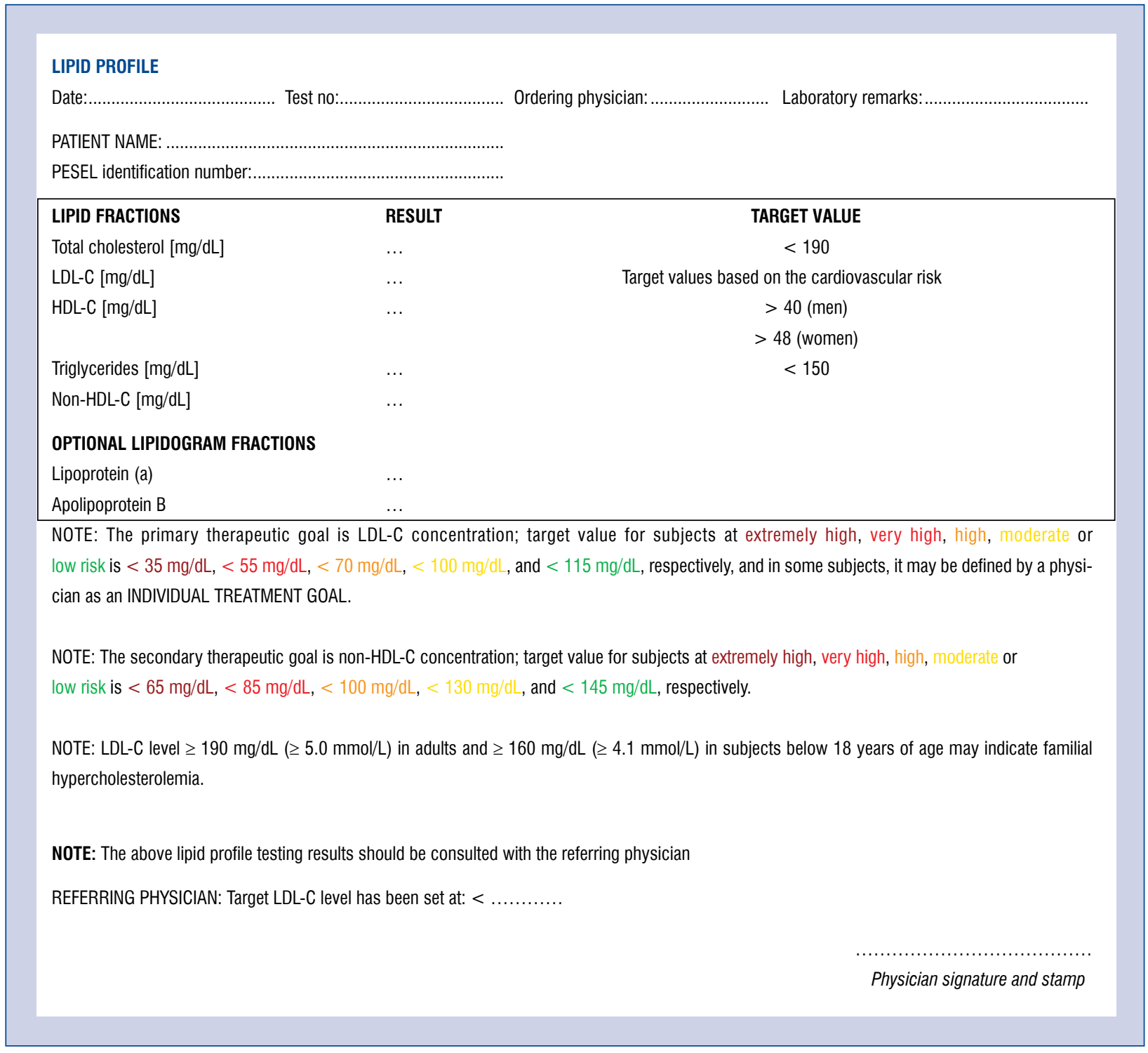

Figure 3. A proposed appropriate form to report lipid profile testing results; LDL-C - low-density lipoprotein cholesterol; HDL-C — high-density lipoprotein cholesterol; non-HDL-C — non-high-density lipoprotein cholesterol.

In severe hypertriglyceridemia, intake of all fat should be significantly reduced due to the presence of chylomicrons.

An important adjunct to lifestyle modifications (appropriate dietary treatment and adequate physical activity) may be the use of a product based on plant substances with lipid-lowering effects supported by evidence-based medicine (EBM) data. These currently include preparations containing monacolin $\mathrm{K}$ and bergamots products. Monacolin, a constituent of red yeast rice is natural lovastatin, which may reduce LDL-C level by $20 \%$. Bergamot is a type of orange from Calabria. The extract of this fruit has a beneficial effect on lipid profile and carbohydrate metabolism. Another example of non-drug treatment relates to proper sleep hygiene (6-8 hours/day/adult), reducing exposure to air pollution, and quitting smoking. It should be remembered that in addition to smoking cessation recommendations, pharmacological interventions (cytisine, nicotine replacement therapy, bupropion, varenicline), some kind of alternative in the treatment of smoking patients who continue to smoke despite the aforementioned interventions, can be offered as alternative harm reduction products which heat tobacco instead of burning it (heat-not-burn, e.g., IQOS - approved, for example, by the American Food and Drug Administration) [29]. 
Table 4. The impact of food products on the reduction of low-density lipoprotein cholesterol (LDL-C) (adapted from: [26], modified)

\begin{tabular}{|c|c|}
\hline Food & Effect on LDL-C \\
\hline Foods high in n-6 PUFA and/or MUFA and low in SFA; e.g., canola oil & Moderate to large reduction \\
\hline Foods high in soluble fiber; e.g., psyllium, oats, and barley & Moderate reduction \\
\hline Foods with added plant sterols or stanols & Moderate reduction \\
\hline Flaxseeds (whole) & Small to moderate reduction \\
\hline Soy protein & Small to moderate reduction \\
\hline Tomatoes & Small to moderate reduction \\
\hline Almonds & Small reduction \\
\hline Fish & No clear effect \\
\hline Decaffeinated coffee (in place of regular coffee) & No effect \\
\hline Filtered coffee & No effect \\
\hline Foods high in SFA or trans fatty acids (i.e., solid and tropical fats) & Moderate to large increase \\
\hline Unfiltered coffee (in place of filtered coffee) & Moderate to large increase \\
\hline Avocados & Moderate to large reduction \\
\hline Turmeric & Moderate to large reduction \\
\hline Hazelnuts & Small to moderate reduction \\
\hline Pulses & Small to moderate reduction \\
\hline Green tea & At least small reduction \\
\hline Fiber, whole grains & Small reduction \\
\hline Walnuts & Small reduction \\
\hline Darker roast coffee & No clear effect \\
\hline Fructose (in place of sucrose/glucose) & No clear effect \\
\hline Marine oils (high in long-chain n-3 PUFA) & Very small increase \\
\hline Free sugars & Small increase \\
\hline Coffee (in place of tea) & Small to moderate increase \\
\hline Garlic powder & Small to moderate reduction \\
\hline Probiotics and prebiotics & Small to moderate reduction \\
\hline Cumin & Small to moderate reduction \\
\hline Ginger & Small reduction \\
\hline Eggs & Small increase \\
\hline Foods high in resistant starch & Small reduction \\
\hline High-polyphenol olive oil (in place of low-polyphenol) & Small reduction \\
\hline Foods high in $\alpha$-linolenic acid, e.g., flaxseed oil & No clear effect \\
\hline Foods high in medium-chain (in place on of long-chain) SFA & No clear effect \\
\hline Grapefruits & No effect \\
\hline Berries & Small to moderate reduction \\
\hline Garlic & Small to moderate reduction \\
\hline Black tea & At least small reduction \\
\hline Dark chocolate/cocoa products & At least small reduction \\
\hline Alcoholic drinks & Small reduction \\
\hline Dairy products (all, high-fat, low-fat) & No clear effect \\
\hline Grape polyphenols & No clear effect \\
\hline Synbiotics & No clear effect \\
\hline Whey protein & No clear effect \\
\hline Fruit juice & No effect \\
\hline Red meat & No effect \\
\hline Sweeteners & No effect \\
\hline
\end{tabular}

MUFA — monounsaturated fatty acids; PUFA — polyunsaturated fatty acids; SFA — saturated fatty acids 
6. Statins are the basis of lipid-lowering pharmacotherapy. In accordance with the wording of previous Declarations of Sopot [1-3], we continue to endorse and highlight the recommendation for statins as the major drugs used to treat hypercholesterolemia. They account for more than $90 \%$ of all lipid-lowering drugs prescribed in Poland, and their use has been increasing year by year. Statins reduce hepatic cholesterol synthesis by competitive inhibition of 3-hydroxy-3-methylglutarylcoenzyme A (HMG-CoA) reductase. They are among the best studied drugs used for cardiovascular disease prevention, and their beneficial effect on cardiovascular mortality has been shown in multiple clinical trials. Of HMG-CoA reductase inhibitors used in Poland, rosuvastatin and atorvastatin have the most effective lipid-lowering effect.

The smallest recommended rosuvastatin dose, $5-10 \mathrm{mg}$, is equivalent to $20-30 \mathrm{mg}$ of atorvastatin. It means that the conversion of the lipid-lowering efficacy of rosuvastatin to atorvastatin corresponds more to a ratio of $1: 3$ than $1: 2$. Thus, the availability of $15 \mathrm{mg}$ and $30 \mathrm{mg}$ rosuvastatin doses increases the ability to switch statin therapy to this drug in those patients who were previously treated with $40 \mathrm{mg}$ and $80 \mathrm{mg}$ of atorvastatin, respectively. These intermediate statin doses allow more effective attainment of target LDL-C levels by individualizing the therapy. An increase has been recently seen in the intensifying of lipid-lowering therapy by prescriptions of intermediate statin doses by practitioners. Atorvastatin undergoes hepatic biotransformation by the cytochrome 450 (CYP) 3A4 isoform, while rosuvastatin is metabolized in the liver to a much lesser degree, interacting with CYP2C9. These differences are important due to potential drug interactions which are very rare with rosuvastatin. Rosuvastatin is contraindicated in patients with severe renal failure and glomerular filtration rate (GFR) below $30 \mathrm{~mL} / \mathrm{min} / 1.73 \mathrm{~m}^{2}$. A mnemonic distinction "atorvastatin safer in a patient with kidney disease" and "rosuvastatin safer in a patient with liver disease" is still popular and may be helpful in choosing a specific molecule (results from the PLANET I and PLANET II studies still await publication). However, it would not be reasonable, by oversimplifying this rule in practice, to refrain from the use of the most effective lipid-lowering drug available on the market (rosuvastatin) in those patients in whom renal function allows it (i.e., with the estimated GFR $>30 \mathrm{~mL} / \mathrm{min}$ ) [30,31]. The need to use a statin in kidney and heart transplant patients should not be forgotten. Many of the standard immunosuppres- sive drugs increase or cause lipid disorders. Some, such as cyclosporine and tacrolimus, may increase the levels of concomitant statins. Thus, it is necessary to be vigilant in terms of possible adverse effects and to individualize the dosing schedule of lipid-lowering drugs.

The major goal of the treatment of dyslipidemia is to lower LDL-C level. As indicated by the new recommendations in the present document, treatment goals are currently very rigorous and only the use of potent drugs in high doses may help achieve or approach these goals. If the goal is not achieved, the dose should be increased or statin should be switched to a more effective treatment in reducing LDL-C. Regarding atorvastatin and rosuvastatin, their use in maximal doses was shown to induce regression of atherosclerotic lesions in diseased coronary vessels (ASTEROID and SATURN studies) [32, 33].

In 2021, another statin will be available in Poland - pitavastatin. Pitavastatin lowers LDL-C $>50 \%$, placing it in the group of high-intensity statins, in addition to atorvastatin and rosuvastatin. It is also worth underling its negligible effect on glycemia and the low risk of drug interactions. Pitavastatin is contraindicated only in patients being treated with cyclosporine and lopinavir/ritonavir. Caution is advised in combination therapy with fibrates. The objection to pitavastatin is noted in a relatively small number of randomized clinical trials, limited primarily to people of the Asian race.

Familial hypercholesterolemia requires intensive lipid-lowering treatment, regardless of the genetic test result. The therapeutic goal in subjects with $\mathrm{FH}$ depends on the assessment of cardiovascular risk. Patients with FH with ASCVD or other major risk factors are in a very high-risk group and the goal is to reduce LDL-C $\geq 50 \%$ and below $55 \mathrm{mg} / \mathrm{dL}$. Subjects with $\mathrm{FH}$ but without the aforementioned factors are in the high-risk category with the goal of reducing LDL-C $\geq 50 \%$ and below $70 \mathrm{mg} / \mathrm{dL}$ [4].

The first-line drugs are effective statins (rosuvastatin and atorvastatin), the next step is combined therapy with ezetimibe $[4,34]$. In the case of $\mathrm{FH}$ patients with a very high risk who do not achieve the treatment goal on the maximally tolerated combined therapy with a potent statin and ezetimibe, and in those with statin intolerance, PCSK9 inhibitors should be included, this is reimbursed in Poland under drug programs. In terms of newer therapies, high efficacy has also been demonstrated for inclisiran, administered by injection once every 6 months, belonging to 
the small interfering ribonucleic acid (siRNA) type and bempedia acid acting on the ATP-citrate lyase. Moreover, evinacumab, a human monoclonal antibody inhibiting angiopoietin-like proteins 3 (ANGPTL3), with a specific potential role in the coexistence of hypercholesterolemia with hypertriglyceridemia is a new direction $[4,35,36]$. There are lipid-lowering drugs with separate mechanisms, which are unavailable in Poland, and are dedicated to homozygous, severe family hypercholesterolemia (e.g., mipomersen).

It should be underlined that the primary goal of treating patients with $\mathrm{FH}$ is to prevent cardiovascular events through early diagnosis and effective treatment.

7. Elevated lipoprotein (a) concentration is associated with an increased cardiovascular risk. Lipoprotein (a) is a particle similar to LDL, however, unlike it, it additionally contains apolipoprotein (a), which is evolutionarily derived from plasminogen and may influence the fibrinolysis process. Increased $\mathrm{Lp}(\mathrm{a})$ levels are associated with an increased number of cardiovascular events, independent of LDL-C levels and other risk factors. It is estimated that 1 in 5 people have a concentration of $\mathrm{Lp}(\mathrm{a})>50 \mathrm{mg} / \mathrm{dL}$, and a very high concentration of $\mathrm{Lp}(\mathrm{a})>180 \mathrm{mg} / \mathrm{dL}$ even 1 in 100 people [36, 37]. The $L P A$ locus on chromosome 6 (6q26-27) is one of the strongest determinants of CAD. It has been revealed that the relationship between $L P A$ gene variants and cardiovascular events was maintained in people with LDL-C $\leq 70 \mathrm{mg} / \mathrm{dL}$ on statin therapy [38].

Determination of $\mathrm{Lp}(\mathrm{a})$ concentration should be considered in every adult once in a lifetime to early identify patients with very high $\mathrm{Lp}$ (a) levels $>180 \mathrm{mg} / \mathrm{dL}$ and cardiovascular risk comparable to those with HeFH [4]. However, the determination of $\mathrm{Lp}(\mathrm{a})$ should be performed in particular in patients with:

- a burdening family history of premature ASCVD;

- a moderate to high cardiovascular risk;

- premature ASCVD or recurrent despite optimal LDL-C control;

- family history of high $\mathrm{Lp}(\mathrm{a})>90 \mathrm{mg} / \mathrm{dL}$ in a first-degree relative [39].

Cardiovascular risk related to $\mathrm{Lp}(\mathrm{a})$ concentration can be estimated as low, moderate, high, and very high based on its ranges (Table 5) [40].

Lifestyle modification, including diet and physical activity, have minimal effect on $\mathrm{Lp}$ (a) concentration. Currently, commercially available drugs reduce $\mathrm{Lp}$ (a) levels to an unsatisfactory degree, and lipoprotein apheresis is effective among the therapies
Table 5. Cardiovascular risk related to lipoprotein (a) concentration.

\begin{tabular}{llc}
\hline \multicolumn{2}{c}{ Lipoprotein (a) } & $\begin{array}{c}\text { Effect on cardiovascular } \\
\text { risk }\end{array}$ \\
\cline { 1 - 2 }$[\mathrm{mg} / \mathrm{dL}]$ & {$[\mathrm{nmol} / \mathrm{L}]$} & \\
\hline $18-40$ & $32-90$ & Low \\
$40-90$ & $90-200$ & Moderate \\
$90-180$ & $200-400$ & High \\
$>180$ & $>400$ & Very high \\
\hline
\end{tabular}

Table 6. Examples of therapies lowering lipoprotein (a).

\begin{tabular}{lcc}
\hline Therapy & $\begin{array}{c}\text { Reduction of } \\
\text { lipoprotein (a) } \\
\text { concentration }\end{array}$ & $\begin{array}{c}\text { Effect on the } \\
\text { reduction of } \\
\text { cardiovascular } \\
\text { events }\end{array}$ \\
\hline Niacin & $19-39 \%$ & $\begin{array}{c}\text { No reduction of } \\
\text { cardiovascular } \\
\text { events }\end{array}$ \\
PCSK & $20-30 \%$ & $\begin{array}{c}\text { Sub-analyzes from } \\
\text { clinical trials indicate } \\
\text { inhibitors }\end{array}$ \\
reduction in cardio- \\
vascular events in \\
patients with lipopro- \\
tein (a) $>100$ mg/dL \\
Long-term therapy \\
reduces the annual \\
rate of major adverse \\
apheresis
\end{tabular}

PCSK 9 - proprotein convertase subtilisin/kexin type 9

available in Poland (Table 6). Particularly ineffective in the fight against elevated levels of $\mathrm{Lp}(\mathrm{a})$ are statins. Previous analyzes indicate that a $100 \mathrm{mg} / \mathrm{dL}$ reduction in $\mathrm{Lp}(\mathrm{a})$ should translate into a long-term $45 \%$ reduction in cardiovascular risk. Currently, in phase 3 of clinical trials, there are new drugs targeting apolipoprotein (a) (antisense oligonucleotide and siRNA), which may reduce $\mathrm{Lp}$ (a) concentration by up to $90 \%$ (pelacarsen, olpasiran) [40-45].

8. Statin tolerance is the rule with few exceptions. All statins, including the most effective ones - atorvastatin and rosuvastatin, are very well tolerated by patients, and the incidence of specific adverse effects is rare. However, the statin group is burdened with a strong nocebo effect, and the frequency of reported adverse effects is not increased with blinded drug administration compared to placebo, which has been proven in the recent SAMSON study. 
However, patients should be informed about symptoms associated with rare clinically significant adverse effects of statins. Symptoms, especially those related to muscles, are the reason for the treatment discontinuation, despite their mild nature and the proven strong benefits of statins in preventing cardiovascular events. Muscle symptoms appear in 5-20\% of patients treated with statins according to clinical trial data and usually affect the proximal muscles of the limbs and back, are symmetrical, and may have various other symptoms (pain, cramps, stiffness, weakness). Characteristically, symptoms appear after starting a statin and disappear after stopping its use. Rhabdomyolysis is a rare, serious complication (1-3/100,000 patients/year) characterized by a combination of pain and high levels of CK exceeding 10 times the upper limit of normal. A complication of rhabdomyolysis may be acute kidney injury. Notably, myoglobinuria is currently not a necessary condition for the diagnosis of rhabdomyolysis [46-48].

Muscle-related statin intolerance is defined as an intolerance to at least three different statins, also statins at reduced doses. One of the most important risk factors for muscle symptoms after statins are interactions with commonly used drugs, i.e., fibrates (gemfibrozil), macrolide antibiotics (erythromycin, clarithromycin), antifungal drugs (fluconazole, itraconazole), as well as cyclosporine, amiodarone, verapamil, diltiazapem, amlodipine, nefazodone, danazol, ranolazine, selected protease inhibitors in the treatment of HIV infection. Other factors, such as older age $>75$ years, female sex, low body mass index, impaired kidney and liver function, history of muscle ailments, diabetes, HIV infection, type and dose of statin, hypothyroidism, acute infection, low vitamin D3 levels also contribute to the symptoms after statins. The CK determination should be included in the algorithm for the management of muscle symptoms after statins. In the case of 10 fold increase in values above the upper limit, regardless of muscle ailments, the statin should be discontinued and renal function, as well as CK, monitored every 2 weeks until normalization. Subsequently, it is advised to re-include the statin.

In the case of muscle symptoms and elevation of CK 4 to 10 times above the norm, statin withdrawal should be considered until symptoms resolve and CK normalization. After CK normalization, a different statin can be included at a lower dose. If symptoms recur and treatment goals are not achieved, it should be considered to add ezetimibe to a statin followed by a PCSK9 inhibitor. These drugs can also be used as monotherapy [49]. If CK remains elevated, the diagnosis of myopathy and further neurological, endocrine, and rheumatological diagnosis should be considered.

However, in the case of persistent muscle ailments and CK values below 4 times the upper limit, a temporary withdrawal of the statin for a period of 6 weeks may be considered. Subsequently, after the symptoms have resolved, the same or a different statin, at a lower dose, may be used. As an alternative, a regimen of atorvastatin or rosuvastatin at lower doses of $5-10 \mathrm{mg} /$ day, with a frequency of 1-3 times per week, should be considered [4].

The determination of vitamin D3 concentration and compensation for its deficiency, as well as supplementation with coenzyme Q10, may be considered. It should always be determined whether the increase in CK has not occurred after physical activity.

With this approach, more than $90 \%$ of people are able to tolerate statins. Therefore, it seems that true statin intolerance affects only a few percent of patients [27]. Particularly, in the case of muscle symptoms after statins, the nocebo effect also plays a dominant role, thus establishing a causal relationship has to be criticized.

Another adverse effect of statins is a mild increase in ALT, which affects $0.5-2 \%$ of patients, most often after high-dose potent statins. A clinically significant increase in ALT activity 3 times above the norm requires a temporary withdrawal of the statin until ALT normalizes. However, statin hepatotoxicity has not been proven to be significant, and progression to hepatic failure is extremely rare.

In monitoring patients on high-intensity statin therapy or with insulin resistance, metabolic syndrome, obesity, are contraindicated to forget about periodic glycemic or HbA1c monitoring.

In the case of adverse effects after statins, it is particularly important to educate patients and underline the undeniable benefits of using them and the low risk of direct life-threatening symptoms [4].

9. Non-statin treatment options of dyslipidemia: PCSK9 inhibitors, ezetimibe, fenofibrate, icosapent, inclisiran, and lipoprotein apheresis are an important part of the treatment. Notably, although statin treatment is very effective, it does not always allow achieving the goal lipid levels when administered as monotherapy, even using the most potent statins. When attempting to reach the target LDL-C level, an 
alternative approach to increasing the dose and choosing the most potent statin is to add a selective cholesterol absorption inhibitor, ezetimibe, to statin. Following oral administration, ezetimibe binds to the intestinal brush border and selectively inhibits intestinal absorption of cholesterol and plant sterols, which results in reduced cholesterol transport to the liver. In patients with hypercholesterolemia, ezetimibe significantly reduces TC, LDL-C, apoB, and triglyceride levels, and increases HDL-C level. The IMPROVE-IT study showed that the combination of ezetimibe with even one of the oldest statins, simvastatin, led to a much higher number of patients achieving the target LDL-C level, and resulted in a lower high-sensitivity C-reactive protein level compared to patients who received statin monotherapy [50]. In addition, these additional benefits of reduced inflammation translated to better outcomes in patients receiving a combination treatment, with a lower risk of major cardiovascular events and mortality. According to the current European guidelines, ezetimibe is also recommended as an alternative drug in patients intolerant to statins and in patients who do not reach target LDL-C levels despite statin treatment.

Another treatment approach that clearly deserves increasing attention is the use of PCSK9 inhibitors. Their target protein, PCSK9, is involved in the metabolism of LDL receptors (LDLR). An increased PCSK9 level/function reduces LDLR expression by promoting lysosomal catabolism and increases plasma LDL-C level. Available PCSK9 inhibitors, which are monoclonal antibodies against PCSK9, reduce LDL-C level by about $60 \%$ regardless of the use of other lipid-lowering therapies [51]. Recent trials with PCSK9 inhibitors showed that very low LDL-C levels achieved with the use of these drugs are associated with a reduced cardiovascular event rate and a reduction of atherosclerotic lesions (plaque volume) in coronary arteries [52-54]. Candidates for this treatment are patients at a very high total cardiovascular risk, subjects with $\mathrm{HeFH}$ (and also some subjects with homozygous $\mathrm{FH}$ ) receiving maximum tolerated doses of first and second-line drugs and/or treated with apheresis, and those intolerant to statins, in whom LDL-C levels are persistently high. Nevertheless, despite the proven effectiveness of PCSK9 inhibitors, wider use of this modern therapy is hampered by economic barriers and lack of reimbursement except for two drug programs - their range has recently been significantly expanded, which gives hope that Polish patients, similarly to patients in other European countries, will have access to this modern therapy.

A very promising therapeutic option for patients with primary hypercholesterolemia and mixed dyslipidemia is inclisiran registered in December 2020 in Europe. This drug belongs to the siRNA group and inhibits the synthesis of the PCSK9 protein in the liver. Inclisiran has been shown in ORION clinical trial to reduce LDL-C by approximately $50 \%$ with a low percentage of adverse effects, mainly related to injection site reactions ( 1 per 10 people). It should be underlined that the dosage of the drug is revolutionary in lipidlowering drugs - it is administered twice a year, which solves the problem of non-compliance - one of the most important issues with statins.

It should be remembered that in patients with atherogenic dyslipidemia, statin monotherapy does not fully protect them from cardiovascular events. In these patients, the optimal therapy, particularly with concomitant diabetes or metabolic syndrome, is a combination of a statin and fenofibrate which helps achieve the secondary treatment goal of non-HDL-C level normalization [55]. The recently published results of the ACCORDION study suggest a possible effect of fenofibrate added to a statin on the reduction of long-term total mortality in diabetics [56].

If isolated severe hypertriglyceridemia is present, treatment is started with fibrate monotherapy, which is also a prevention of acute pancreatitis.

For patients with triglyceride levels of 135$-499 \mathrm{mg} / \mathrm{dL}$ in the high and very high-risk categories, the use of omega- 3 unsaturated fatty acids (eicosapentaenoic acid ethyl ester $2 \times 2 \mathrm{~g} / \mathrm{d}$ ) in combination with statins should be considered. These drugs can lower triglyceride levels by as much as $30-45 \%$.

As revealed in the REDUCE-IT study, icosapent (eicosapentaenoic acid ethyl ester, unavailable in Poland) used in a dose of $2 \mathrm{~g}$ twice a day in combination with a statin significantly reduced the risk of cardiovascular events and lowered triglyceride level by $18 \%$. These data cannot be extrapolated to other doses and other omega- 3 preparations, in general not showing an effect on clinical adverse events. Therapy with omega- 3 acids is safe, and the adverse effects comprise mainly gastrointestinal disorders [4].

The last form of treatment that should be mentioned here is lipoprotein apheresis. Lipoprotein apheresis is a very effective procedure for extracorporeal purification of the blood or plasma from LDL, very-low-density-lipoprotein and $\mathrm{Lp}(\mathrm{a})$ 


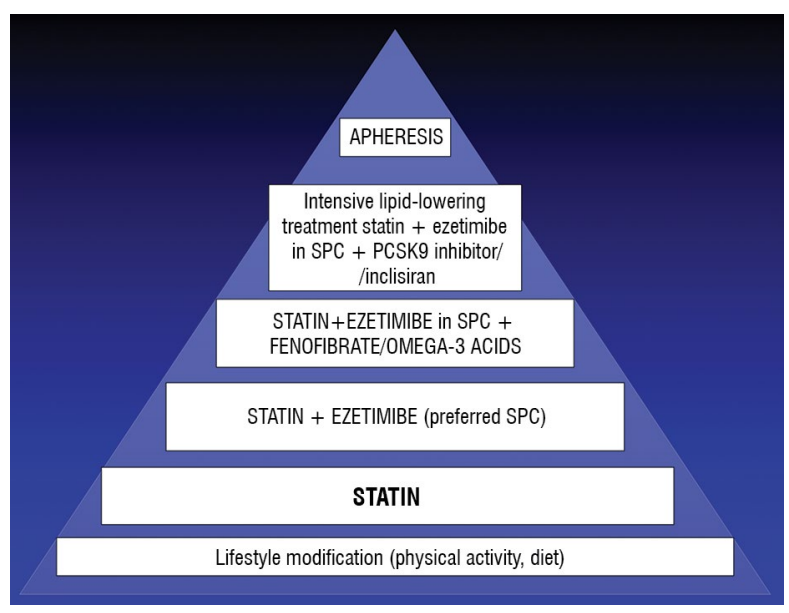

Figure 4. Pyramid of lipid-lowering pharmacotherapy; PCSK9 - proprotein convertase subtilisin/kexin type 9; SPC - single-pill combinations.

particles, but it must be systematically repeated every $1-2$ weeks. About $60-80 \%$ of LDL-C and $\mathrm{Lp}$ (a) can be removed at one time. Lipoprotein apheresis should be considered in patients who, despite the maximum dose of hypolipidemic drugs and diet, still have LDL-C levels above the recommended target. However, it is currently a therapy dedicated rather to patients with a high concentration of $\mathrm{Lp}(\mathrm{a})>100 \mathrm{mg} / \mathrm{dL}$ and with ASCVD.

In conclusion, the basis for lipid profile modification and treatment interventions in dyslipidemia is graphically summarized on a lipid-lowering therapy pyramid (Fig. 4). Physical activity and lifestyle modification, and subsequently — statin treatment, statin treatment in combination with another lipid-lowering drug (ezetimibe/fenofibrate/ /omega-3 acids) and eventually supplementing the pharmacotherapy with another modern lipidlowering drug (PCSK9 inhibitors/inklisiran) are the standard of patient care. PCSK9 inhibitors, alirocumab, and evolocumab have already been introduced into routine treatment in drug programs in two indications: certain clinical diagnosis of $\mathrm{FH}$ and after myocardial infarction (detailed criteria are described in point 10 of the Declaration).

10. With advances in medicine and drug therapy, it is possible to achieve a significant improvement of the effectiveness of dyslipidemia treatment in Poland. Nonetheless, as mentioned in the introduction, therapeutic goals of dyslipidemia treatment continue to be achieved at an unsatisfactory rate, only slightly above $10 \%$, also among high-risk patients. It is thus particularly important to identify the reasons for this poor dyslipidemia control in our country. The most common errors of statin therapy include therapeutic nihilism, statin doses that are too low, statins that are too weak, and treatment discontinuation in case of muscle symptoms occurrence after statins [57]. Although lipid-lowering treatment should mostly be continued indefinitely in patients with established cardiovascular disease, in many of them the statin dose is reduced (usually after a follow-up testing shows that the target LDL-C level has been achieved) or the drug is discontinued.

Recently, with advances in drug therapy, new therapeutic options have become available which may potentially improve patient compliance and at least partially reduce difficulties with achieving target lipid levels. Most notably, these include intermediate statin doses (rosuvastatin 15 and $30 \mathrm{mg}$ ) which allow fine tuning of the intensity of the lipid-lowering effect and determining the optimal dose for a given patient and single-pill combinations (SPC). The latter in particular has been a major breakthrough on the pharma market. Currently, the following SPC containing two lipidlowering drugs in one tablet are available in Poland:

- atorvastatin and ezetimibe;

- rosuvastatin and ezetimibe.

Particularly important is the appearance on the market of SPC rosuvastatin and ezetimibe, which contains the highest permitted doses of these drugs (SPC R/E 40/10).

According to a new statement of the European Atherosclerosis Society (EAS) working group, in the group of patients who suffered from ASCVD with LDL-C concentration $\geq 100 \mathrm{mg} / \mathrm{dL}$, who have not previously received lipid-lowering therapy (including statins in monotherapy), combination therapy with a high-intensive statin with ezetimibe is recommended as first-line therapy (Fig. 5) [58]. However, the priority of achieving the maximum tolerated dose of statins should be remembered.

In addition, it should be noted that since 2019, a treatment program of $\mathrm{FH}$ with PCSK9 inhibitors has been implemented in Poland. These drugs are fully reimbursed if specific criteria are met. Two preparations of PCSK9 inhibitors are available in Poland: alirocumab and evolocumab. These drugs constitute the third line of hypercholesterolemia treatment and the status after myocardial infarction when the current treatment with a statin (first-line drug) and ezetimibe (second-line drug added to a statin) does not achieve the treatment goal recommended by the physician.

Inclusion criteria in the $\mathrm{FH}$ drug treatment program (all criteria must be met): 


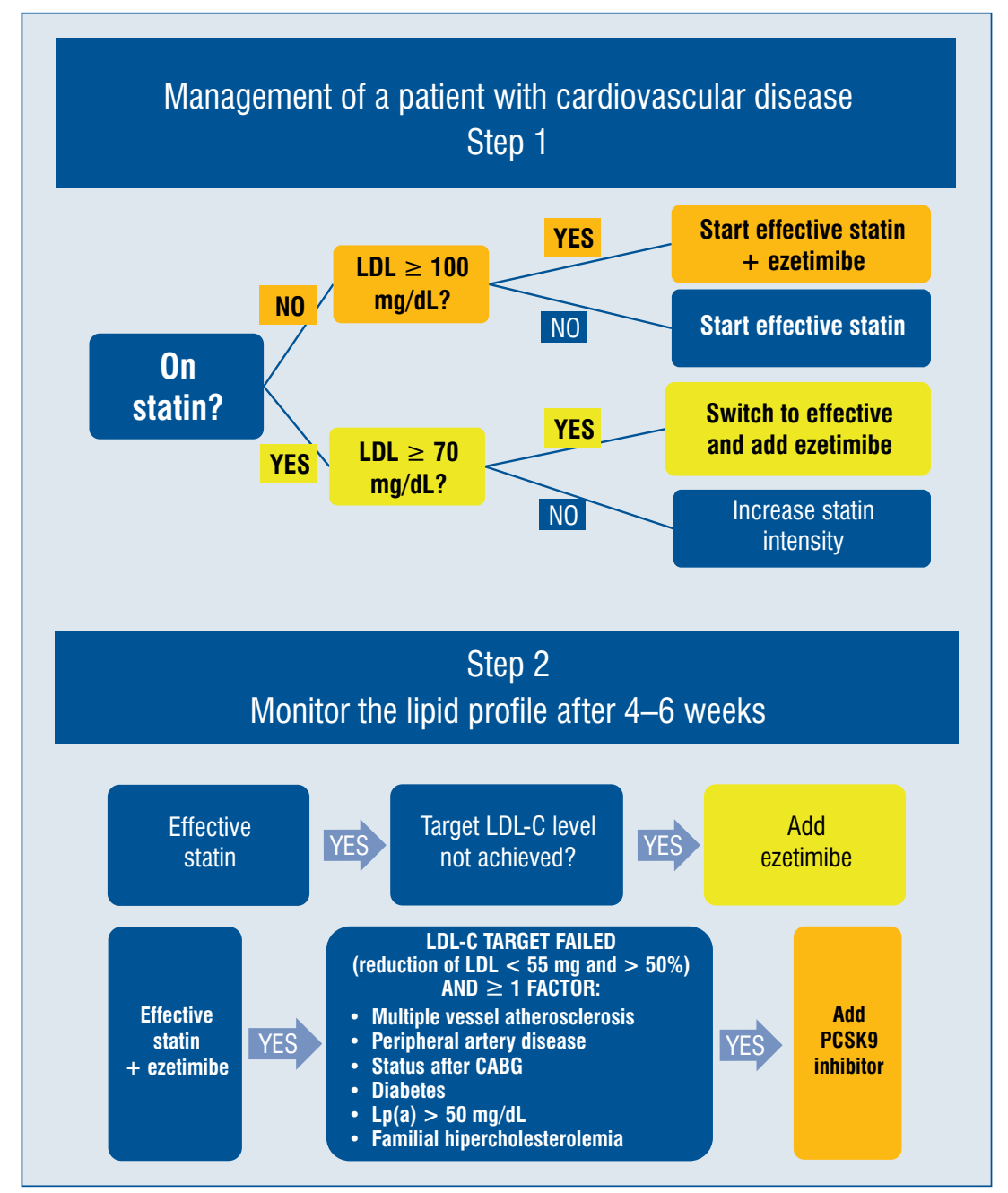

Figure 5. A new dyslipidemia treatment algorithm proposed by the European Atherosclerosis Society (EAS) 2021 (adapted from: [58], modified); LDL - low density lipoprotein; LDL-C - low density lipoprotein cholesterol; CABG — coronary artery bypass grafting; Lp(a) - lipoprotein (a); PCSK9 — proprotein convertase subtilisin/kexin type 9.

1) age $\geq 18$ years;

2) certain diagnosis of $\mathrm{HeFH}$, i.e. $>8$ points in the DLCN scale;

3) meeting the eligibility criteria for LDL apheresis treatment, and for patients already treated, meeting these criteria at initiation of LDL apheresis treatment;

4) eligibility criteria for LDL apheresis: LDL-C $>100 \mathrm{mg} / \mathrm{dL}(2.5 \mathrm{mmol} / \mathrm{L})$ despite diet and:

a) intensive statin therapy at maximum doses, i.e. atorvastatin $80 \mathrm{mg}$ or rosuvastatin $40 \mathrm{mg}$, followed by atorvastatin $40-80 \mathrm{mg}$ or rosuvastatin $20-40 \mathrm{mg}$ in combination with ezetimibe $10 \mathrm{mg}$; used for a total of 3 months, including combination therapy for a minimum of 1 month b) intensive statin therapy at maximum tolerated doses, followed by combination therapy with ezetimibe $10 \mathrm{mg}$, for a total of 3 months, including combination therapy for a minimum of 1 month.

In addition, in recent months, the program has been extended to include patients with a very high risk of cardiovascular diseases. Criteria for inclusion in the drug program of patients with very high cardiovascular risk (all of the following must be met):

1) age $\geq 18$ years;

2) $\mathrm{LDL}-\mathrm{C}>100 \mathrm{mg} / \mathrm{dL}(2.5 \mathrm{mmol} / \mathrm{L})$ despite diet and intensive treatment with statins at the maximum tolerated doses, followed by statins at the maximum tolerated doses in combination with ezetimibe. A total treatment period 
of at least 3 months is required, including at least 1 month of combination therapy (statin at maximum tolerated doses + ezetimibe). For patients with suspected statin-related rhabdomyolysis, the treatment period is determined by the treating physician in accordance with the guidelines of the European Society of Cardiology (ESC)/EAS;

3) a history of invasively diagnosed myocardial infarction, which occurred up to 12 months before enrollment in the drug program, and

a) with an additional history of myocardial infarction and multivessel coronary artery disease, defined as $\geq 50 \%$ stenosis in $\geq 2$ vessels

or

b) with atherosclerotic disease of non-coronary arteries, understood as:

- $\quad$ peripheral artery disease, i.e.:

- intermittent claudication with ankle-brachial index $<0.85$, or

- previous revascularization of peripheral arteries, or

- limb amputation due to atherosclerotic disease; or

- cerebral artery disease, i.e.:

- previous ischemic stroke, or

- transient ischaemic attack.

Patients who are currently treated with evolocumab or alirocumab and who were eligible for the drug program at the time of initiation of the treatment with evolocumab or alirocumab and who did not meet the criteria described in section 3 may also be qualified for the drug program to ensure treatment continuation.

11. Lipid-lowering treatment is significant in the COVID-19 pandemic era. Ever since the outbreak of the pandemic, it was underlining that chronic treatment of dyslipidemia should be continued in every subject infected with severe acute respiratory syndrome coronavirus 2 (SARS-CoV-2). However, the pandemic resulted in a confirmed deterioration in the control of cardiovascular risk factors, an increase in therapeutic inertia, and the ignoring of the necessary control of effects and the need for treatment escalation. There were studies suggesting that the additional immunomodulatory and anti-inflammatory properties of statins may aid in the treatment of COVID-19. However, such data have not yet been verified in controlled, prospective clinical trials. Retrospective studies show the benefits of statins in COVID-19 patients, which could be based on their:

- anti-inflammatory effect (reducing the concentrations of interleukin [IL] 6, IL-8, affecting the activation of $\mathrm{T}$ lymphocytes);

- anticoagulant effect (increase in nitric oxide excretion, improvement in endothelial function, effect on platelet aggregation, decrease in the production of type 1 plasminogen activator inhibitor);

- potential effect of reducing SARS-CoV-2 virus entry (several contradictory theories related to modifying the composition of cell membranes);

- potential effect on angiotensin converting enzyme 2 (ACE2) expression;

- other mechanisms, e.g. the described inhibitory effect of statins on Mpro - the main protease of SARS-CoV-2 virus (it is not known whether the levels of statins present in the body have this effect).

Limited access to a physician should force appropriate modifications to the present treatment algorithms so that a patient with dyslipidemia, in the COVID-19 era, receives effective treatment as soon as possible, which could be continued in the teleconsultation system. Therefore, it seems rational to shorten the procedure algorithms as much as possible, even when it is not officially recommended by the scientific society. It seems that effective treatment should be given as soon as possible, especially in groups of high, very high, and extremely high cardiovascular risk patients. Thus, an approach may be considered in which, for example, an injection to lower LDL-C (PCSK9 inhibitors) should be administered with a statin on the first day of treatment, upon admission. Such administration of evolocumab (the best tested PCSK9 inhibitors in acute myocardial infarction) ensures that normolipemia (correct, target LDL-C is achieved already during hospitalization instead of many weeks after leaving the hospital. Likewise, a patient with high cardiovascular risk and a high baseline LDL-C level should, in principle, receive the statin and ezetimibe combination straight away, rather than waiting several weeks for the effectiveness of the statin to be determined. This reasoning is presented in the three models below, which are a specific interpretation of the current treatment guidelines in Europe. 


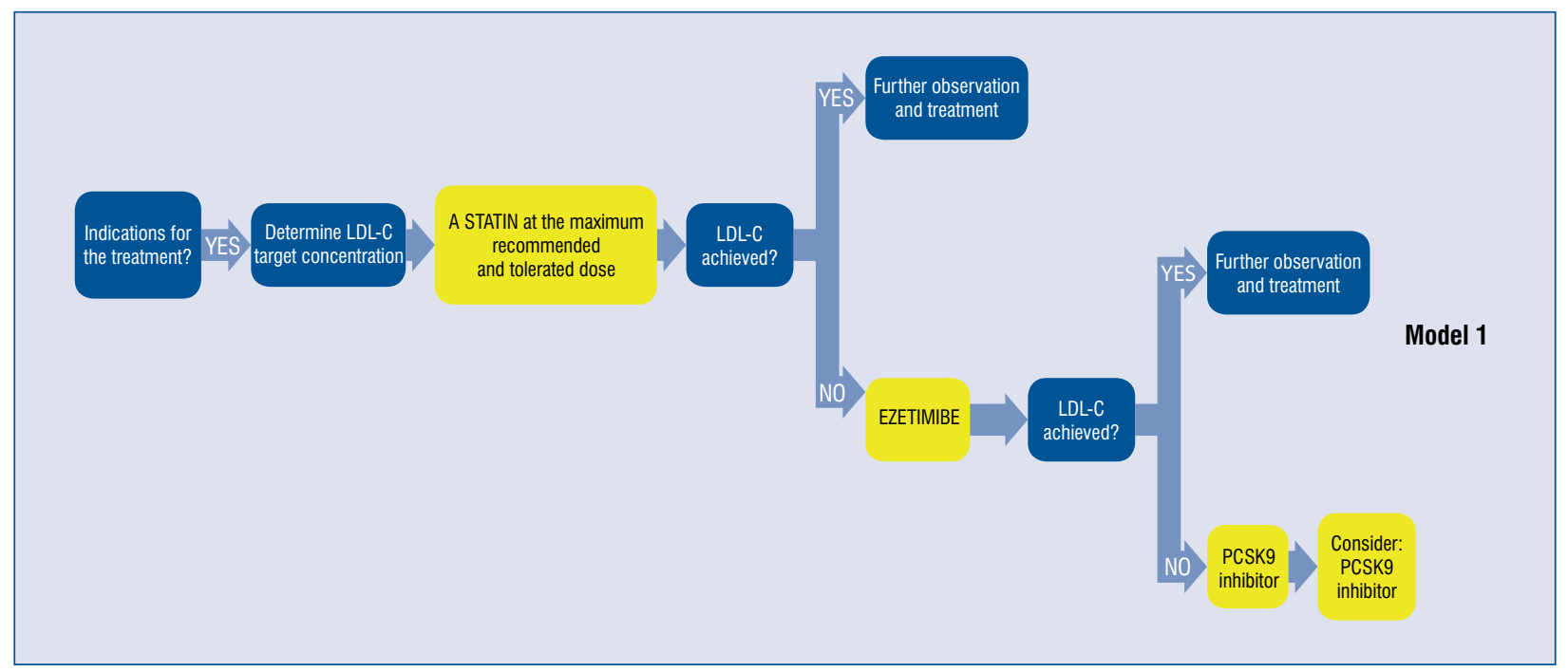

Figure 6. The first model - a three-stage algorithm for the treatment of hypercholesterolemia, promoted and in force for cardiologists from 2019 in Europe; mandatory model in 2020, developed by European Society of Cardiology (ESC) (adapted from: [4], modified); LDL-C — low density lipoprotein cholesterol; PCSK9 — proprotein convertase subtilisin/kexin type 9 .

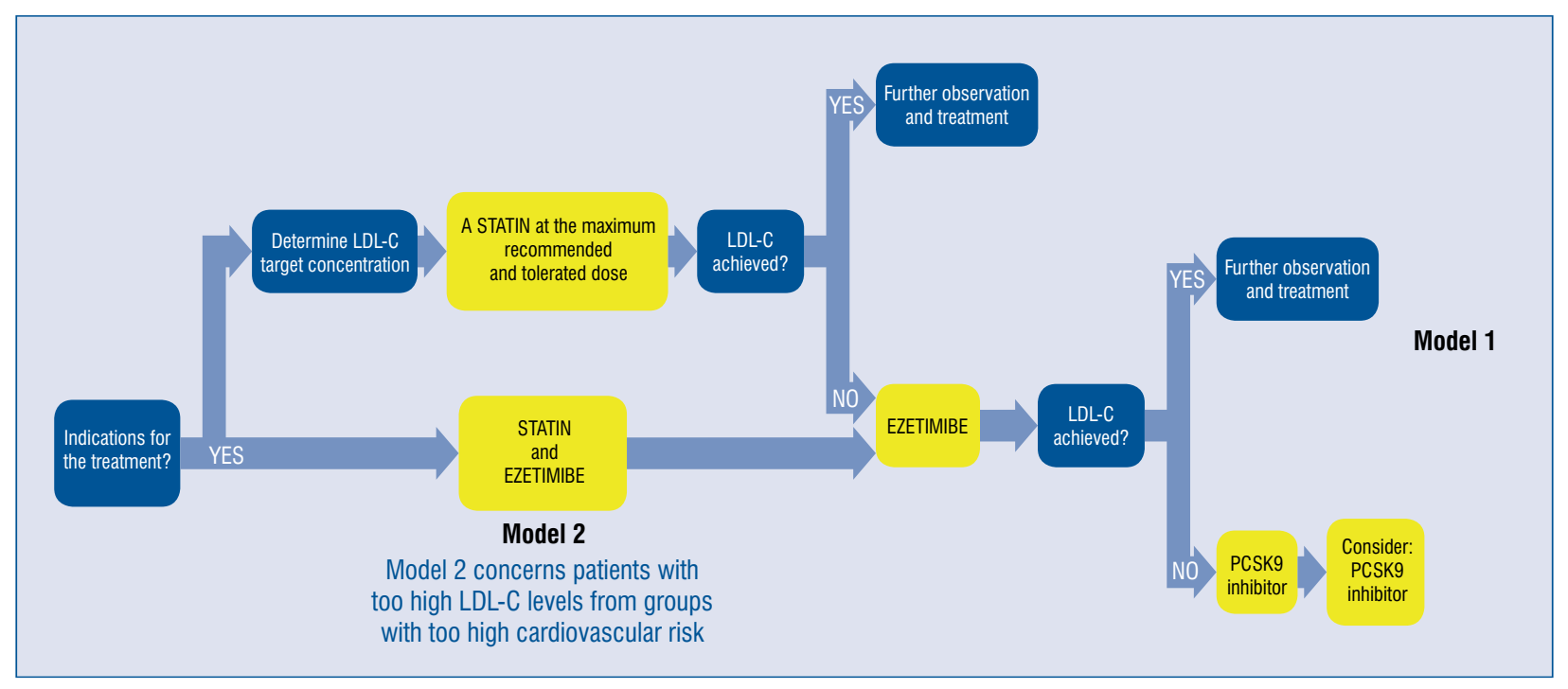

Figure 7. The second model — accelerated algorithm for possible treatment with a proprotein convertase subtilisin/ /kexin type 9 (PCSK9) inhibitor; developed on the basis of the European Society of Cardiology (ESC) model from 2020 (adapted from: [4], modified) by Krzysztof J. Filipiak; LDL-C — low density lipoprotein cholesterol.

The first model (Fig. 6) [4] is based on the current guidelines of the European Society of Cardiology and recommends starting therapy with a statin, adding ezetimibe (a second oral drug with a different mechanism of action) after a few weeks, and in case of treatment failure - the introduction of additional injections of a PCSK9 inhibitors.

In the current situation, in the era of COVID-19, it is not possible, in many cases, to wait a few weeks for achieving the lipid target (problem with contact with the ordering physician or family physician), it is also not worth starting treatment in patients with even the highest dose of a statin when we know that it will not achieve the lipid target anyway. In such cases, it is worth using the second model - accelerate the algorithm - administer a statin with ezetimibe immediately and check in a few weeks whether the addition of a PCSK9 inhibitors is required (Fig. 7). 


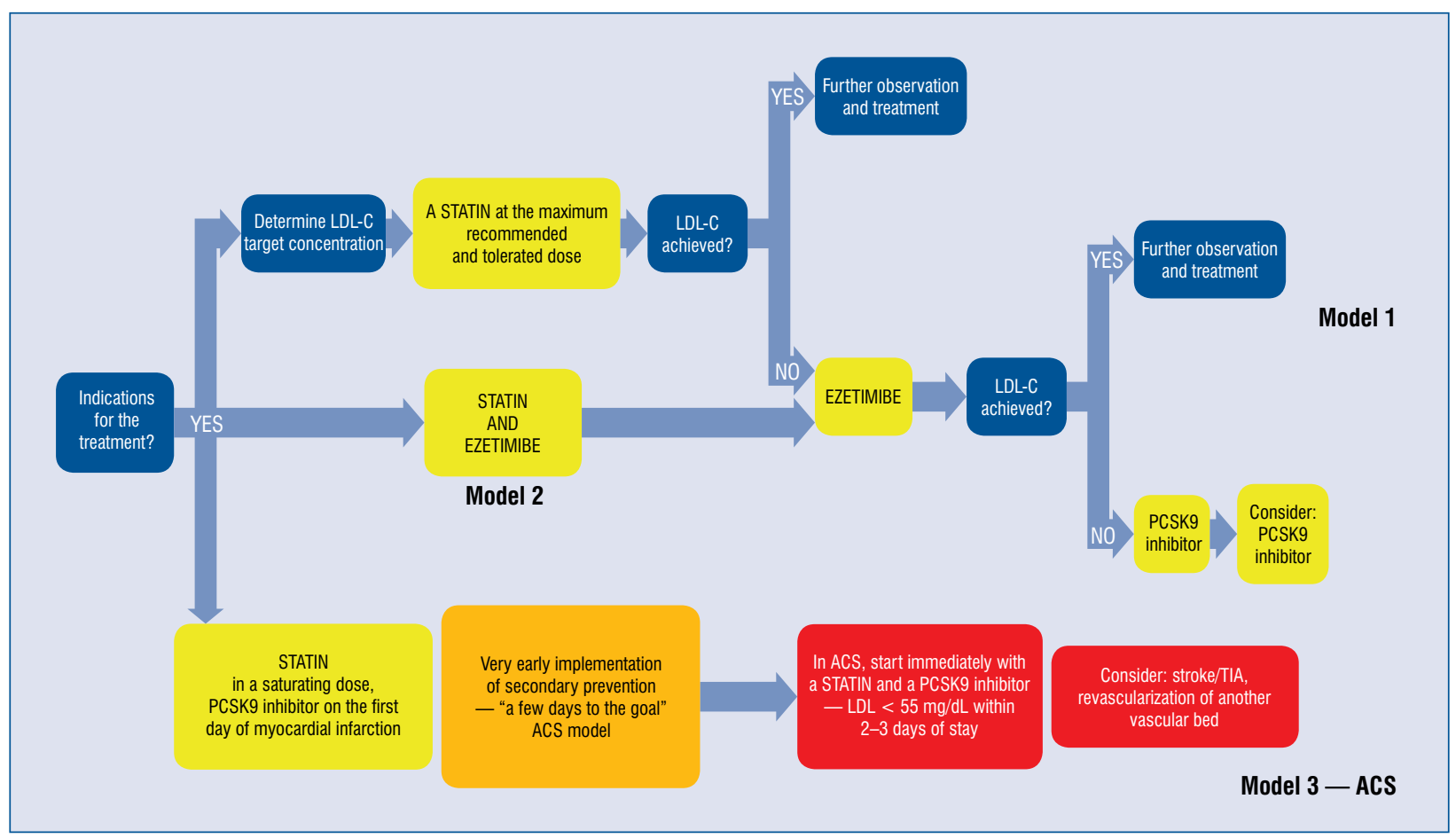

Figure 8. The third model — proposed therapeutic management for patients with acute coronary syndromes (ACS) — early administration of a proprotein convertase subtilisin/kexin type 9 (PCSK9) inhibitor simultaneously with a statin; developed on the basis of the European Society of Cardiology (ESC) model from 2020 (adapted from: [4], modified) by Krzysztof J. Filipiak; the model to be considered also in other patients in the future - those with stroke, transient ischemic attack (TIA) of the central nervous system, revascularization of another vascular bed; LDL-C — low density lipoprotein cholesterol.

However, it seems that this is insufficient for the highest-risk patients - such as those with acute myocardial infarction. Based on the EVOPACS and EVACS studies with evolocumab, we can currently postulate that the combined administration of a high dose of a statin and an injection of evolocumab immediately upon admission to the hospital. Some experts see no space for ezetimibe here anymore. The combination of a statin and evolocumab allows the majority of treated patients to achieve optimal LDL-C $<55 \mathrm{mg} / \mathrm{dL}$ already during the 3-4-day of hospitalization. It was the basis of the third model we proposed for patients with acute coronary syndromes (Fig. 8).

The proposed, modified management algorithms could facilitate the care of patients with dyslipidemia in the times of COVID-19. Limited contact with a physician is not conducive to optimal care, it hampers the implementation of the drug program with PCSK9 inhibitor dedicated to patients with $\mathrm{FH}$, as well as the new drug program with PCKS9 inhibitor dedicated to patients at high cardiovascular risk, which is to enter into practice in the last months of 2021.
Conflict of interest: Filip M. Szymański - Participation in satellite sessions/workshops: Bausch Health, Sanofi, Adamed, Krka, Sandoz Polska, Zentiva, Viatris (Mylan), USP Zdrowie sp. $z$ o.o.; Agnieszka Mickiewicz - Honorarium payments for lectures, participation in satellite sessions and consulting groups: Krka, Sanofi, Amgen, Novartis, Zentiva, Egis, Servier; Grzegorz Dzida - Participation in satellite sessions/workshops: Krka, Polpharma, Viatris (Mylan); Iwona Gorczyca-Głowacka - None declared; Dariusz Kozłowski - None declared; Krystyna Widecka - None declared; Zbigniew Krasiński - None declared; Adam Kobayashi — None declared; Dagmara Hering — None declared; Katarzyna Mizia-Stec - None declared; Jarosław D. Kasprzak - Honorarium payments for lectures, participation in satellite sessions and consulting groups: Amgen, Sanofi, Polpharma, Servier, Pfizer, Aflofarm, AstraZeneca, Novartis; Tomasz Zubilewicz - None declared; Krzysztof Narkiewicz - Participation in satellite sessions/ /workshops: Egis, Krka, Servier; Marek Koziński None declared; Anna E. Płatek - None declared; Anna Ryś-Czaporowska - None declared; Beata 
Chełstowska - None declared; Stefan Grajek None declared; Marcin Wełnicki - Honorarium payments for lectures, training sessions, educational resources for the pharmaceutical companies: Egis, AstraZeneca, Novartis, Novo Nordisk, Apotex, Aurotivas, Polpharma, Bayer, Berlin-Chemie Menarini, Boehringer Ingelheim, Krka, Pfizer, Sanofi-Aventis, Servier, Teva, Valeant; Artur Mamcarz - Participation in satellite sessions and consulting groups of the following Polish and European drugs manufacturers: Adamed, Amgen, AstraZeneca, Bausch Health, Bayer, Berlin-Chemie Menarini, Boehringer Ingelheim, Egis, Krka, Merck, Mylan, Sandoz, Sanofi-Aventis, Servier, Zentiva; Marcin Barylski - None declared; Beata Wożakowska-Kapłon - Honorarium payments for lectures, participation in satellite sessions and consulting groups, clinical research sponsored by the following drugs manufacturers: Adamed, Alfasigma, Amgen, AstraZeneca, Bausch Health, Bayer, Berlin-Chemie Menarini, Boehringer Ingelheim, Egis, Krka, Novartis, Pfizer, Sanofi-Aventis, Servier; Miłosz J.Jaguszewski - None declared; Marcin Gruchała None declared; Krzysztof J. Filipiak — Participation in satellite sessions, Polish and European consulting groups, clinical-research and research grants sponsored by the following manufacturers of drugs and diagnostic tests: Adamed, Alfasigma, Amgen, AstraZeneca, Bausch Health, Bayer, Berlin-Chemie Menarini, Boehringer Ingelheim, Egis, Krka, Merck, Mylan, Sandoz, Sanofi, Servier, Zentiva.

\section{References}

1. Wożakowska-Kapłon B, Filipiak KJ, Mamcarz A, et al. [Actual problems of dyslipidaemia treatment in Poland - 2nd Declaration of Sopot. Experts' Group Consensus endorsed by the Polish Cardiac Society Working Group on Cardiovascular Pharmacotherapy] [Article in Polish]. Kardiol Pol. 2014; 72(9): 847-853, doi: 10.5603/KP.2014.0182, indexed in Pubmed: 25231425.

2. Filipiak KJ, Cybulska B, Dudek D, et al. Aktualne problemy terapii dyslipidemii w Polsce - Deklaracja Sopocka. Stanowisko ekspertów wsparte przez Sekcję Farmakoterapii SercowoNaczyniowej Polskiego Towarzystwa Kardiologicznego. Choroby Serca i Naczyń. 2011; 8: 1-4.

3. Szymański FM, Barylski M, Cybulska B, et al. Recommendation for the management of dyslipidemia in Poland - Third Declaration of Sopot. Interdisciplinary Expert Position Statement endorsed by the Polish Cardiac Society Working Group on Cardiovascular Pharmacotherapy. Cardiol J. 2018; 25(6): 655-665, doi: 10.5603/CJ.2018.0141, indexed in Pubmed: 30600830.

4. Mach F, Baigent C, Catapano AL, et al. 2019 ESC/EAS Guidelines for the management of dyslipidaemias: lipid modification to reduce cardiovascular risk. Eur Heart J. 2020; 41(1): 111-188, doi: 10.1093/eurheartj/ehz455, indexed in Pubmed: 31504418.

5. Akioyamen LE, Genest J, Shan SD, et al. Estimating the prevalence of heterozygous familial hypercholesterolaemia: a systematic review and meta-analysis. BMJ Open. 2017; 7(9): e016461, doi: 10.1136/bmjopen-2017-016461, indexed in Pubmed: 28864697.

6. McGowan MP, Hosseini Dehkordi SH, Moriarty PM, et al. Diagnosis and treatment of heterozygous familial hypercholesterolemia. J Am Heart Assoc. 2019; 8(24): e013225, doi: 10.1161/ JAHA.119.013225, indexed in Pubmed: 31838973.

7. Bruckert É, Gallo A. L'hypercholestérolémie familiale. Bull Acad Natle Méd. 2017; 201(7-9): 1323-1334, doi: 10.1016/s00014079(19)30398-x.

8. Mickiewicz A, Chmara M, Futema M, et al. Efficacy of clinical diagnostic criteria for familial hypercholesterolemia genetic testing in Poland. Atherosclerosis. 2016; 249: 52-58, doi: 10.1016/j. atherosclerosis.2016.03.025, indexed in Pubmed: 27062410.

9. Rynkiewicz A, Cybulska B, Banach M, et al. Polish Lipid Expert Forum. [Management of familial heterozygous hypercholesterolaemia. Position paper of the Polish Lipid Expert Forum] [Article in Polish]. Kardiol Pol. 2013; 71(1): 107-111, indexed in Pubmed: 23348551.

10. Knowles JW, Rader D, Khoury M. Cascade screening for familial hypercholesterolemia and the use of genetic testing. JAMA. 2017; 318(4): 381, doi: 10.1001/jama.2017.8543.

11. Sharifi M, Futema M, Nair D, et al. Polygenic hypercholesterolemia and cardiovascular disease risk. Curr Cardiol Rep. 2019; 21(6): 43, doi: 10.1007/s11886-019-1130-z, indexed in Pubmed: 31011892 .

12. Talmud PJ, Shah S, Whittall R, et al. Use of low-density lipoprotein cholesterol gene score to distinguish patients with polygenic and monogenic familial hypercholesterolaemia: a case-control study. Lancet. 2013; 381(9874): 1293-1301, doi: 10.1016/s01406736(12)62127-8.

13. Futema M, Bourbon M, Williams M, et al. Clinical utility of the polygenic LDL-C SNP score in familial hypercholesterolemia. Atherosclerosis. 2018; 277: 457-463, doi: 10.1016/j.atherosclerosis.2018.06.006, indexed in Pubmed: 30270085.

14. Pająk A, Szafraniec K, Polak M, et al. WOBASZ Investigators. Changes in the prevalence, treatment, and control of hypercholesterolemia and other dyslipidemias over 10 years in Poland: the WOBASZ study. Pol Arch Med Wewn. 2016; 126(9): 642-652, doi: 10.20452/pamw.3464, indexed in Pubmed: 27452484.

15. Kotseva K, Wood D, De Bacquer D, et al. EUROASPIRE Investigators. EUROASPIRE IV: A European Society of Cardiology survey on the lifestyle, risk factor and therapeutic management of coronary patients from 24 European countries. Eur J Prev Cardiol. 2016; 23(6): 636-648, doi: 10.1177/2047487315569401, indexed in Pubmed: 25687109.

16. Reiner $\check{Z}$, De Backer G, Fras Z, et al. EUROASPIRE Investigators. Lipid lowering drug therapy in patients with coronary heart disease from 24 European countries--Findings from the EUROASPIRE IV survey. Atherosclerosis. 2016; 246: 243-250, doi: 10.1016/j.atherosclerosis.2016.01.018, indexed in Pubmed: 26812002.

17. Bandosz P, O'Flaherty M, Drygas W, et al. Decline in mortality from coronary heart disease in Poland after socioeconomic transformation: modelling study. BMJ. 2012; 344: d8136, doi: 10.1136/ bmj.d8136, indexed in Pubmed: 22279114.

18. Catapano AL, Graham I, De Backer G, et al. ESC Scientific Document Group. 2016 ESC/EAS Guidelines for the management of dyslipidaemias. Eur Heart J. 2016; 37(39): 2999-3058, doi: 10.1093/eurheartj/ehw272, indexed in Pubmed: 27567407.

19. Kolovou GD, Mikhailidis DP, Kovar J, et al. Assessment and clinical relevance of non-fasting and postprandial triglycerides: an expert panel statement. Curr Vasc Pharmacol. 2011; 9(3): 
258-270, doi: 10.2174/157016111795495549, indexed in Pubmed: 21314632.

20. Stroes ES, Thompson PD, Corsini A, et al. European Atherosclerosis Society Consensus Panel. Statin-associated muscle symptoms: impact on statin therapy-European Atherosclerosis Society Consensus Panel Statement on Assessment, Aetiology and Management. Eur Heart J. 2015; 36(17): 1012-1022, doi: 10.1093/eurhearti/ehv043, indexed in Pubmed: 25694464.

21. Piepoli MF, Hoes AW, Agewall S, et al. Authors/Task Force Members:, Authors/Task Force Members, Additional Contributor: Simone Binno (Italy), Document Reviewers:. 2016 European Guidelines on cardiovascular disease prevention in clinical practice: The Sixth Joint Task Force of the European Society of Cardiology and Other Societies on Cardiovascular Disease Prevention in Clinical Practice (constituted by representatives of 10 societies and by invited experts): Developed with the special contribution of the European Association for Cardiovascular Prevention \& Rehabilitation (EACPR). Eur J Prev Cardiol. 2016; 23(11): NP1-NP96, doi: 10.1177/2047487316653709, indexed in Pubmed: 27353126.

22. Visseren FLJ, Mach F, Smulders YM, et al. ESC Scientific Document Group, ESC Scientific Document Group. 2021 ESC Guidelines on cardiovascular disease prevention in clinical practice. Eur Heart J. 2021; 42(34): 3227-3337, doi: 10.1093/eurheartj/ ehab484, indexed in Pubmed: 34458905.

23. Garber AJ, Abrahamson M, Barzilay J, et al. Consensus Statement by the American Association of Clinical Endocrinologists and American College of Endocrinology on the Comprehensive type 2 Diabetes Management Algorithm - 2017 Executive Summary. Endocr Pract. 2017; 23(2): 207-238, doi: 10.4158/ ep161682.cs.

24. Robinson JG, Rosenson RS, Farnier M, et al. Safety of very low low-density lipoprotein cholesterol levels with alirocumab: pooled data from randomized trials. J Am Coll Cardiol. 2017; 69(5): 471-482, doi: 10.1016/j.jacc.2016.11.037, indexed in Pubmed: 28153102.

25. Brunner FJ, Waldeyer C, Ojeda F, et al. Multinational Cardiovascular Risk Consortium. Application of non-HDL cholesterol for population-based cardiovascular risk stratification: results from the Multinational Cardiovascular Risk Consortium. Lancet. 2019; 394(10215): 2173-2183, doi: 10.1016/S0140-6736(19)32519-X, indexed in Pubmed: 31810609.

26. Schoeneck M, Iggman D. The effects of foods on LDL cholesterol levels: a systematic review of the accumulated evidence from systematic reviews and meta-analyses of randomized controlled trials. Nutr Metab Cardiovasc Dis. 2021; 31(5): 1325-1338, doi: 10.1016/j.numecd.2020.12.032, indexed in Pubmed: 33762150.

27. Stefanick ML, Mackey S, Sheehan M, et al. Effects of diet and exercise in men and postmenopausal women with low levels of HDL cholesterol and high levels of LDL cholesterol. N Engl J Med. 1998; 339(1): 12-20, doi: 10.1056/NEJM199807023390103, indexed in Pubmed: 9647874.

28. Varady KA, Jones PJH. Combination diet and exercise interventions for the treatment of dyslipidemia: an effective preliminary strategy to lower cholesterol levels? J Nutr. 2005; 135(8): 18291835, doi: 10.1093/jn/135.8.1829, indexed in Pubmed: 16046704.

29. Szymanski FM, Semczuk-Kaczmarek K, Kuna P. "Health outcomes in COPD smokers using heated tobacco products: a 3-year follow-up: comment”. Intern Emerg Med. 2021 [Epub ahead of print], doi: 10.1007/s11739-021-02753-5, indexed in Pubmed: 33983473 .
30. deZeeuw D. Different renal protective effects of atorvastatin and rosuvastatin in diabetic and non-diabetic renal patients with proteinuria. Results of the PLANET trials. 2010 European Dialysis and Transplant Association Congress. Munich, Germany, June 27, 2010.

31. Abe M, Maruyama N, Okada K, et al. Effects of lipid-lowering therapy with rosuvastatin on kidney function and oxidative stress in patients with diabetic nephropathy. J Atheroscler Thromb. 2011; 18(11): 1018-1028, doi: 10.5551/jat.9084, indexed in Pubmed: 21921413.

32. Nissen SE, Nicholls SJ, Sipahi I, et al. ASTEROID Investigators. Effect of very high-intensity statin therapy on regression of coronary atherosclerosis: the ASTEROID trial. JAMA. 2006; 295(13): 1556-1565, doi: 10.1001/jama.295.13.jpc60002, indexed in Pubmed: 16533939.

33. Nicholls SJ, Ballantyne CM, Barter PJ, et al. Effect of two intensive statin regimens on progression of coronary disease. N Engl J Med. 2011; 365(22): 2078-2087, doi: 10.1056/NEJMoa1110874, indexed in Pubmed: 22085316.

34. Mickiewicz A, Futema M, Ćwiklinska A, et al. Higher responsiveness to rosuvastatin in polygenic versus monogenic hypercholesterolaemia: a propensity score analysis. Life (Basel). 2020; 10(5), doi: 10.3390/life10050073, indexed in Pubmed: 32443900.

35. Wójcik C. Emerging lipid lowering agents targeting LDL cholesterol. Postgrad Med. 2020 [Epub ahead of print], doi: 10.1080/00325481.2020.1751422, indexed in Pubmed: 32243228.

36. Surma S, Romańczyk M, Filipiak KJ. Angiopoietin-like proteins inhibitors: new horizons in the treatment of atherogenic dyslipidemia and familial hypercholesterolemia. Cardiol J. 2021 [Epub ahead of print], doi: 10.5603/CJ.a2021.0006, indexed in Pubmed: 33470417.

37. Kamstrup PR, Tybjaerg-Hansen A, Steffensen R, et al. Genetically elevated lipoprotein(a) and increased risk of myocardial infarction. JAMA. 2009; 301(22): 2331-2339, doi: 10.1001/ jama.2009.801, indexed in Pubmed: 19509380.

38. Wei WQ, Li X, Feng Q, et al. LPA variants are associated with residual cardiovascular risk in patients receiving statins. Circulation. 2018; 138(17): 1839-1849, doi: 10.1161/CIRCULATIONAHA.117.031356, indexed in Pubmed: 29703846.

39. Nicholls SJ, Bubb KJ. The riskier lipid: what is on the HORIZON for lipoprotein (a) and should there be $\mathrm{Lp}$ (a) screening for all? Curr Cardiol Rep. 2021; 23(8): 97, doi: 10.1007/s11886-02101528-w, indexed in Pubmed: 34196823.

40. Cegla J, Neely RD, France M, et al. HEART UK Medical, Scientific and Research Committee. HEART UK consensus statement on lipoprotein(a): a call to action. Atherosclerosis. 2019; 291: 62-70, doi: 10.1016/j.atherosclerosis.2019.10.011, indexed in Pubmed: 31704552.

41. Rhainds D, Brodeur MR, Tardif JC. Lipoprotein (a): when to measure and how to treat? Curr Atheroscler Rep. 2021; 23(9): 51, doi: 10.1007/s11883-021-00951-2, indexed in Pubmed: 34235598.

42. Leebmann J, Roeseler E, Julius U, et al. Pro(a)LiFe Study Group*. Lipoprotein apheresis in patients with maximally tolerated lipidlowering therapy, lipoprotein(a)-hyperlipoproteinemia, and progressive cardiovascular disease: prospective observational multicenter study. Circulation. 2013; 128(24): 2567-2576, doi: 10.1161/ CIRCULATIONAHA.113.002432, indexed in Pubmed: 24056686.

43. Moriarty PM, Gray JV, Gorby LK. Lipoprotein apheresis for lipoprotein(a) and cardiovascular disease. J Clin Lipidol. 2019; 13(6): 894-900, doi: 10.1016/j.jacl.2019.09.010, indexed in Pubmed: 31753721 . 
44. Mickiewicz A, Marlega J, Kuchta A, et al. Cardiovascular events in patients with familial hypercholesterolemia and hyperlipoproteinaemia (a): Indications for lipoprotein apheresis in Poland. J Clin Apher. 2021; 36(3): 370-378, doi: 10.1002/jca.21872, indexed in Pubmed: 33386762.

45. Szarek M, Bittner VA, Aylward P, et al. ODYSSEY OUTCOMES Investigators. Lipoprotein(a) lowering by alirocumab reduces the total burden of cardiovascular events independent of low-density lipoprotein cholesterol lowering: ODYSSEY OUTCOMES trial. Eur Heart J. 2020; 41(44): 4245-4255, doi: 10.1093/eurheartj/ ehaa649, indexed in Pubmed: 33051646.

46. Banach M, Mikhailidis DP. Statin intolerance: some practical hints. Cardiol Clin. 2018; 36(2): 225-231, doi: 10.1016/j. ccl.2017.12.004, indexed in Pubmed: 29609752.

47. Alonso R, Cuevas A, Cafferata A. Diagnosis and management of statin intolerance. J Atheroscler Thromb. 2019; 26(3): 207-215, doi: 10.5551/jat.RV17030, indexed in Pubmed: 30662020.

48. Ward NC, Watts GF, Eckel RH, et al. Statin toxicity. Circ Res. 2019; 124(2): 328-350, doi: 10.1161/CIRCRESAHA.118.312782, indexed in Pubmed: 30653440.

49. Diaconu CC, Iorga RA, Furtunescu F, et al. Statin intolerance: new data and further options for treatment. Curr Opin Cardiol. 2021; 36(4): 487-493, doi: 10.1097/HCO.0000000000000874, indexed in Pubmed: 33929368.

50. Bohula EA, Giugliano RP, Cannon CP, et al. Achievement of dual low-density lipoprotein cholesterol and high-sensitivity C-reactive protein targets more frequent with the addition of ezetimibe to simvastatin and associated with better outcomes in IMPROVE-IT. Circulation. 2015; 132(13): 1224-1233, doi: 10.1161/CIRCULATIONAHA.115.018381, indexed in Pubmed: 26330412.

51. Navarese EP, Kolodziejczak M, Kereiakes DJ, et al. Proprotein convertase subtilisin/kexin type 9 monoclonal antibodies for acute coronary syndrome: a narrative review. Ann Intern
Med. 2016; 164(9): 600-607, doi: 10.7326/M15-2994, indexed in Pubmed: 26999484.

52. Robinson JG, Farnier M, Krempf M, et al. ODYSSEY LONG TERM Investigators. Efficacy and safety of alirocumab in reducing lipids and cardiovascular events. N Engl J Med. 2015; 372(16): 1489-1499, doi: 10.1056/NEJMoa1501031, indexed in Pubmed: 25773378.

53. Sabatine MS, Giugliano RP, Wiviott SD, et al. Open-Label Study of Long-Term Evaluation against LDL Cholesterol (OSLER) Investigators. Efficacy and safety of evolocumab in reducing lipids and cardiovascular events. N Engl J Med. 2015; 372(16): 1500-1509, doi: 10.1056/NEJMoa1500858, indexed in Pubmed: 25773607.

54. Norata GD, Tibolla G, Catapano AL. Targeting PCSK9 for hypercholesterolemia. Annu Rev Pharmacol Toxicol. 2014; 54: 273293, doi: 10.1146/annurev-pharmtox-011613-140025, indexed in Pubmed: 24160703.

55. Szymański F, Filipiak K, Wożakowska-Kapłon B, et al. Dyslipidemia aterogenna w codziennej praktyce - interdyscyplinarny konsensus polskich ekspertów. Folia Cardiol. 2017; 12(1): 33-49, doi: 10.5603/fc.a2016.0106.

56. Zhu L, Hayen A, Bell KJL. Legacy effect of fibrate add-on therapy in diabetic patients with dyslipidemia: a secondary analysis of the ACCORDION study. Cardiovasc Diabetol. 2020; 19(1): 28, doi: 10.1186/s12933-020-01002-x, indexed in Pubmed: 32138746.

57. Sliz D, Filipiak KJ, Naruszewicz M, et al. Standards of statin usage in Poland in high-risk patients: 3ST-POL study results. Kardiol Pol. 2013; 71(3): 253-259, doi: 10.5603/KP.2013.0037, indexed in Pubmed: 23575780.

58. Averna M, Banach M, Bruckert E, et al. Practical guidance for combination lipid-modifying therapy in high- and very-high-risk patients: A statement from a European Atherosclerosis Society Task Force. Atherosclerosis. 2021; 325: 99-109, doi: 10.1016/j. atherosclerosis.2021.03.039, indexed in Pubmed: 33892925. 